\title{
More dense but less walkable: the impact of macroscale walkability indicators on recent designs of emirati neighborhoods
}

\author{
Khaled Galal Ahmed ${ }^{1,2^{*}}$ and S. M. Hossein Alipour ${ }^{1,3}$
}

\begin{abstract}
With the aim to enhance sustainability in general including walkability, the recent urban forms of the designs of the Emirati neighborhoods have been denser and more compact, if compared with the older design models. While there are various guidelines and regulations related to the microscale walkability measures for the urban design of neighborhoods in the Emirates but unfortunately the macroscale walkability measures have not received similar attention. So, to investigate how would these denser and more compact recent neighborhoods designs better perform regarding walkability macroscale measures, the research utilized the urban modelling interface (UMI) walkability simulation tool to calculate the UMI Walkscores of these designs because it considers almost all macroscale factors including both urban morphology and urban planning measures and it also allows for the customization of the types, required catchment distances, and weights of the significance of locally provided amenities. The UMI Walkscores were calculated for the six recent denser and more compact neighborhoods designs and were compared with the UMI Walkscore for a conventionally designed model of urban sprawling neighborhoods. Unexpectedly, it has been found out that urban compactness per se is not a sufficient design measure for enhancing walkability in local neighborhood designs, where much higher compactness and density have achieved disappointing UMI Walkscores. So, it seems that for the recent neighborhoods' designs, little attention was paid to the impact of the street network connectivity measures of Intersection Density, Block Length and the link-to-nodes ratio, on UMI Walkscores, if compared with the main attention paid to increasing FAR through decreasing plot sizes. Meanwhile, the explicit macroscale urban planning measures including the land-use factors of the types, numbers, and the location of amenities, as well as the implicit factors of their destination and global weights seem to be more influential in enhancing the UMI Walkscores but have been less considered when planning these neighborhoods. So, besides considering well-known macroscale urban morphology aspects of street network connectivity and locational distribution of provided amenities, boosting walkability macroscale measures on the design level requires adopting a set of adequately customized measures including the appropriate values of their global and distribution weights. These walkability design weights should be also resilient and continuously reviewed to satisfy the changing needs of the local communities. Based on its findings, the research proposed a five-actions plan to help boost walkability macroscale measures in the design of local urban communities in the UAE.
\end{abstract}

Keywords: Walkability, UMI Walkscore, Neighborhood, Sustainability, Compact urban form, United Arab Emirates

\footnotetext{
*Correspondence: kgahmed@uaeu.ac.ae

${ }^{2}$ Architectural Engineering Department, College of Engineering, United

Arab Emirates University, P. O. Box: 13393, Al Ain, UAE

Full list of author information is available at the end of the article
}

\section{Introduction}

The environmentally deteriorated quality of life in many of today's urban settlements requires urgent actions that aim at generating sustainable and livable communities (American Society of Landscape Architects 2015). 
Achieving a sustainable urban form is perceived as the most significant action towards attaining these sustainable and livable communities (Burton et al. 2013; Neuman 2005). Besides the essential aspects that contributes to the sustainability of the urban form of a settlement, including satisfying the requirements of its residents and allowing them to easily access various locally provided amenities and transport nodes (Allen 2009; Jones and MacDonald 2004; Clerk 2000), the diversified and mixed use of the urban form would satisfy the provision of a healthy mix of residential, commercial, and recreational facilities (Moreno et al. 2021).

On the other hand, urban density and compactness have been recommended in the recent discourse about sustainable urban future where urban densification is encouraged to fight against urban sprawl (URBACT 2019). Considering appropriate density in urban planning, as highlighted by Moreno et al. (2021), would help define the ideal number of people that the developed project can comfortably sustain in terms of the delivery of local amenities and resource consumption. It is believed that the dense and mixed-use urban development would effectively reduce automobile dependency and thus would contribute to more sustainable modes of transportation such as walking and cycling. Therefore, the utilization of high density, mixed-use and short proximity between locally provided amenities in a neighborhood are considered among possible effective strategies that decrease automobile dependency and contributes to the utilization of Human Powered Transport (HPT) that describes the transport of a person using human kinetic energy (Sustainable Design Lab 2020; Singh et al. 2018).

This research is focusing on walkability as the widely spread form of HPT and the most environmental and social friendly means of local mobility. Walkability encourages residents to abandon using their own cars to access locally provided amenities, therefore, it contributes to less polluted environment and help enhance the physical and mental wellbeing of the residents. A growing body of research provides evidence about the relationship between poor walkability of the residential environment and the greater obesity prevalence (Kowaleski-Jones et al. 2018; Kiflen et al. 2018; Schiller 2015; Brookfield 2017). Moreover, it is evident now that pedestrian-friendly communities have enhanced community connectedness and social capital due to the initiated social interlinked relations and networks among residents (Rogers et al. 2013; Masoud 2011; Paranagamage et al. 2014; Mazumdar et al. 2018). Accordingly, Annunziata et al. (2020) and Garau et al. (2020) argued that walkability has an ethical significance as it affects people's well-being through positively shaping their physical and social capabilities and also providing them with healthy aging.
For a neighborhood to be walkable both of its 'macroscale' and 'microscale' walkability measures should be achieved. Annunziata et al. (2020) and Garau et al. (2020) dubbed the macroscale indicators as 'contextual factors' including accessibility to amenities and transit, pedestrian network configuration, and land-use. Meanwhile, they described the microscale indicators as 'intrinsic factors' including sidewalks width and ramps, quality of walkway surfaces, and street furniture.

As for the walkability macroscale measures, Barton (2000) stated that neighborhoods to be walkable they should have good pedestrian network linking the neighborhood services and facilities to houses within walkable catchment distances. Typically, the provided amenities on the neighborhood level would be located in a neighborhood service center. For its land-use, this service center would ideally encompass a public transport stop, a marketplace, a community park, a community hall, a number of shops for daily needs, a small supermarket, a post office counter, a public house, a newsagent, a local bank, a community library, local surgeries, commercial units and other workplaces. The neighborhood services should also include a number of kindergartens, a primary school, play and sports areas for children and youngsters, and allotments (Frey 1999). Concerning the appropriate catchment distance to the locally provided amenities, a recent research revealed that pedestrians favor short, direct routes and prefer to walk no further than $500 \mathrm{~m}$ in ordinary daily situations (Brookfield 2017). But, it is still commonly accepted that the distance between any house front door and the local amenities or a transport node should be within maximum 10 min' walk or about 800 m (Barton 2000). Recently, Moreno et al. (2021) promoted for what they called a '15-min city' and argued that this would boost walkability and achieve the desired proximity and social interactions within cities. For the ease of their analysis, the walkability macroscale indicators could be subsumed into 'urban morphology' and 'urban planning' measures, as adopted in this research. Urban morphology measures mainly encompass the street/pedestrian network characteristics such as street intersection density, bock length and link-to-nodes ratio (Labdaoui et al. 2021). It also contains the floorarea-ratio (FAR), calculated as the ratio of the gross floor area of all neighborhood buildings to the total area of the neighborhood's site, and gross population density, calculated by dividing the total development area in hectares over the target population. Meanwhile, the macroscale urban planning measures include both explicit factors, such as land-use that defines the types and numbers of provided amenities, their locational distribution in the neighborhood plan and their 
catchment distances, as well as the implicit factors of the degree of importance of the amenities to the users (Sustainable Design Lab 2020).

On the other hand, the walkability microscale/finegrain measures include mainly the urban design factors at the neighborhood scale, that help create pedestrianfriendly environment that makes walking pleasant and safe through the provision of good quality and attractive pedestrian infrastructure with continuous, wellmaintained, wide, and free from obstructions pedestrian walkways and greenspaces (Kowaleski-Jones et al. 2018; Brookfield 2017). Labdaoui et al. (2021) added that the careful design of these microscale measures makes them more conducive to comfortable walking. These involve main facilities, such as the ramps and sidewalk dimensions, encouragement facilities such as lighting posts, seating benches, soft and hard scape landscaping, and finally the convenience facilities such as toilets and drinking fountains.

\section{Assessing walkability measures}

Assessing walkability macroscale and/or microscale measures has been a concern for researchers and urban developers alike. Frank et al. (2021) affirmed that after almost 30 years of research about how walkability could be measured, there is still inconsistency of these research results that could be attributed to the usually conflicting used methods. This makes it hard to interpret and compare findings of these research works. The differences among the adopted walkability measuring research methods include the use of perceived or objective environmental data, the selected spatial buffering techniques, and the sort of data used to assess types of amenities and their locations, and the scale of urban development. This, as claimed by Frank et al. (2021), has resulted in contradictory results leading to significant confusion over what policies should be adopted to promote walkability. So, this affirms the need for a proper objective measurement tool of walkability in the built environment. This research is a humble attempt to contribute to responding to this need, even partially. In the following section the currently utilized microscale and macroscale walkability assessment tools are briefly reviewed.

\section{Walkability microscale and macroscale assessment tools}

Microscale walkability measures have been assessed through some various tools as summarized by Labdaoui et al. (2021). First is the Path Environment Audit Tool (PEAT) which utilizes various fine-grain level walkability indicators, but it lacks several comfort indicators such as sidewalk dimensions and materials, and natural shading. Second is The Walking Suitability Assessment Form (WSAF) which examines a limited number of walkability indicators including the presence of trees and street lighting. Third is The Neighborhood Environment Walkability Survey (NEWS) which is mostly used in survey question formats but still does not cover all pedestrian comfort aspects. Fourth is the Pedestrian Environment Data Scan (PEDS) tool that consists of a wide range of indicators but still misses various comfort issues. Fifth is the Neighborhood Sidewalk Assessment Tool (NSAT), which concentrates on comfort indicators that cover the needs of pedestrians with different physical abilities. Sixth is, the pedestrian level of service (PLOS) which assess the quality of the street pedestrian realm. These various neighborhood microscale level tools have been used to satisfy the objectives of certain research as relevant.

For assessing walkability macroscale measures on the neighborhood level, Rundle et al. (2019) mentioned The Built Environment and Health-Neighborhood Walkability Index (BEH-NWI) as an assessment tool which can be utilized for local communities across the USA. The indicators in this tool are based on historical data between 1990 and 2010 for the gross population density that reflects the concentration of services and public transit in close proximity, street intersection density as an indicator of street network connectivity, and destination accessibility including access to transportation nodes. The webbased walk scoring is another important tool assessing walkability macroscale indicators usually through quantitative parameters including intersection density, population density, and distance from amenities (Annunziata et al. 2020 and Garau et al. 2020). Walk scoring is usually utilized in assessing "walking friendless" in the design process of neighborhoods (Sustainable Design Lab 2020). As an example of these web-based walk scoring tools, the Street-Smart Walk Score (SS-WS) revealed that residents living in neighborhoods with the highest walkability scores managed to meet physical activity guidelines over three times more than the neighborhoods which with lowest walkability score. Moreover, it has been found that when people moved to a neighborhood with a 10-point higher SS-WS had increase in transport walking by 16.04 min per week and a decline in their Body Mass Index (Frank et al. 2021).

In 2007, Walk Score, a free, publicly available webbased tool, was founded in the USA to promote walkable neighborhoods and to make it easier for individuals to evaluate walkability and transportation options in a given area (Brown 2015). Walk Score is calculated using quantitatively measurable macroscale indicators such as the types and numbers of provided amenities, catchment distances to these amenities, neighborhood block lengths, and the density of street intersections. Using a decay function, Walk Score first assigns a raw score to each location based on its network distances 
from homes to destinations such as grocery shops, restaurants, bookstores, banks, schools, fitness centers, and parks within 1 mile (about $1.60 \mathrm{~km}$ ) from that location. These raw scores are then normalized from 0 to 100 with adjustment of two street network measures around each location, namely, street intersection density and block length. Higher walkability scores mostly represent areas with more local destinations nearby, where walking is an easy option for shopping and errands. The Walk Score Index assigns a walkability score to each property on a scale of 0-100 (Brown 2015). As a benchmark, a neighborhood with a Walk Score below 25 is considered a fully car dependent neighborhood, while neighborhoods with scores ranges of 25-49, 50-69, 70-89, and 90-100 are suggesting mainly car-dependent, partially walkable, very walkable, and walkers' paradise neighborhoods respectively (Koschinsky et al. 2017; Foundry 2018; Score 2019).

As an indication of the validity of utilizing Walk Score as a tool for assessing walkability macroscale measures, several studies have revealed positive associations of Walk Score with actual walking for transport and with recreational physical activity in small towns. A negative associations of Walk Score with body mass index was also observed (Koohsari et al. 2018). In the USA, walkability is continuing to be a more prevalent factor in both home buying decisions and the placement of new businesses. So, Walk Score is currently considered a helpful tool for planners, realtors, and community members to depict a picture about the community's transportation options (Brown 2015; Trimarchi 2018). Moreover, the Walk Score tool appears to be a valid measure of neighborhood's macroscale walkability indicators outside the USA and Canada, where it is originally applied. In a very recent research, significant positive correlations were observed between the Walk Score tool and environmental attributes relevant to walking in Japan (Koohsari et al. 2018).

While there are various guidelines and regulations related to the microscale walkability measures for the urban design of neighborhoods in the United Arab Emirates (UAE), such as Abu Dhabi Street Design Manuals (Abu Dhabi Urban planning Council 2015) and some Form-based Code research work (Arwa and Khaled 2019), but unfortunately the macroscale walkability measures related to the pedestrian network design and the neighborhood morphology and planning have not received similar attention. From another perspective the Walk Score tool cannot be used locally in the UAE because it is tailored to assess walkability macroscale measures in specific urban contexts. So, as discussed in the following section, the research explored a recently developed reliable walk scoring tool that is customizable to the local urban contexts in terms of the macroscale walkability indicators.

\section{UMI walkscore: a proper walkability macroscale measures scoring tool}

Urban Modeling Interface (UMI) Walkscore is the macroscale walkability scoring tool within the UMI computational simulation plugin for Rhinoceros 3D software. The free for researchers and consultants UMI plugin was initially released by the Sustainable Design Lab of the Massachusetts Institute of Technology (MIT) in 2013 and was developed with support from a National Science Foundation EFRI_SEED project, the MIT Energy Initiative, the Kuwait-MIT Center, the Center for Complex Engineering Systems (CCES) at KACST and MIT and Transsolar Climate Engineering. Its latest version (V2.6) has been recently released. The UMI Walkscore record ranges between 0 and 100 and is calculated by constructing a pedestrian travel network and performing a series of shortest-path calculations using Dijkstra's algorithm. By default, the algorithm tests points of interest for proximity to (customizable) nine North American common local community amenities, namely; schools, restaurants, cafe shops, shopping center, entertainment, parks, banks, and grocery.

The Minimum Catchment Distance in meters 'MinDistanceInMeters' and the Maximum Catchment Distance in meters 'MaxDistanceInMeters' are customizable values that should be defined in the UMI plugin. The 'MinDistanceInMeters' is the distance at which penalties begin to be applied. Its default value of $400 \mathrm{~m}$ means that walking trips of $400 \mathrm{~m}$ or less receive perfect scores. Meanwhile, 'MaxDistanceInMeters' specifies the maximum distance people are willing to walk at all and thus, trips longer than this value will be ignored while trips with lengths close to this value will still receive very low scores. The standard accessibility indicator of walking distances in the UMI Walkscore is set between a quarter mile $(400 \mathrm{~m})$ to one and a half miles $(2400 \mathrm{~m})$ from houses to the provided local amenities. These values, which been proven to be a good indicator of "walking environments" in the USA, are customizable where they could be easily changed to be more proper for other urban environment such as those with hot climates. In the UMI Walkscore, a polynomial distance decay function is used for assigning scores according to the distances between each house entrance and amenities (Sustainble Design Lab 2020).

In addition, each of the types of locally provided amenities has a dedicated layer generated in Rhinoceros 3D and is given four (customizable) parameters affecting the walkability scoring: Name, Uses Parks, Destination Weight, and Global Weight. 'Uses Parks' is expressing the allocated the layer of the parks of the neighborhood 
in the software. Unlike the 'explicit' customizable macroscale urban planning measures of the neighborhood land-use, including the types of amenities and their catchment distances, the Destination Weight and Global Weight are considered as two 'implicit' parameters and both are customizable depending on the urban context. The 'Global Weight' is defining the relative importance of each amenity category. In the default software plugin, amenities of restaurants and groceries are having a Global Weight value of 3, while shopping centers and schools are assigned Global Weight values of 2 and 1 respectively (Sustainble Design Lab 2020). On the other hand, the 'Destination Weight' is another parameter that defines the number of the required destinations to achieve a perfect score for a specific amenity's category, in a JSON array format. It also considers the impact that distances to those destinations would have on the score gained by each amenity's category. Each amenity's destination is assigned a Destination Weight value of 1 . If the number of the required amenities for a specific category is more than 1, then the Destination Weight values would have relative weights. For instance, if the cafe shop category requires 2 destinations to gain a perfect score, then the Destination Weights of them might be 10, 6. This simply means that the gained score for the walk to the nearer cafe shop would be $10 / 6$ of the walk score assigned for the walk to the farther café (Sustainble Design Lab 2020).

With all its above-mentioned walkability indicators, the UMI's Walkscore could be considered as an ideal measuring tool for macroscale walkability in the case of Emirati neighborhoods, because it goes beyond the conventional macroscale measuring methods, which mainly rely on calculating catchment distances and street connectivity for assessing walkability. Such conventional methods might be misleading in some street network configurations. For example, loop and dead-end streets intersections do not improve connectivity despite their contribution to street intersection density (EnviroAtlas 2019). On the other hand, an important advantage of the UMI Walkscore tool over other walkability scoring tools, such as the web-based Walk Score discussed in "Walkability microscale and macroscale assessment tools" Section above, is that it allows for more accurate assessment for walkability through adding customizable relevant 'weights' and catchment distances to the locally provided amenities.

\section{Research problem and questions}

In the last few years, the UAE's federal and local governments have adopted sustainable development plans in various sectors. In specific, the building and urban development sectors have witnessed several sustainability initiatives. Estidama (sustainability in Arabic), is the most important initiative where the Estidama Pearl Community Rating System (PCRS), was developed to help achieve livable and sustainable built environment (Abu Dhabi Urban Planning Council 2019). Another initiative is the Abu Dhabi National Housing Guidelines for Integrated Communities (Abu Dhabi Housing Authority 2016). In these, and maybe all other initiatives, realizing HPT friendly urban communities was an essential pillar through calling for the transition from the conventional unsustainable private car dependent sprawling communities to more compact urban form designs that encourage the utilization of all means of $\mathrm{HPT}$, especially walkability.

It is maintained that the denser and more compact urban forms of the recent designs of urban neighborhoods in the UAE have considered sustainable urbanism principles including the provision of walkability infrastructure and networks. But, except the conventional tools for assessing walkability of neighborhood designs such as measuring catchment distances, block lengths, street network connectivity, there is a lack of a reliable and comprehensive evidence that can assess the expected effectiveness of these urban compact designs on walkability, while still in the design stage, and hence define the different aspects affecting it. As discussed above the UMI Walkscore tool seems capable in satisfying this need. A very recent research (Khaled 2020) has attempted to utilize the UMI's Walkscore tool to investigate the relationship between urban compactness and both walkability and bikeability, in the UAE. Unfortunately, this research has only used FAR as a sole indicator leaving behind examining the effect of other walkability macroscale influential factors including morphological measures such as block length, street intersection density, link-tonodes ratio. Also, the research only examined one recent neighborhood design, which would not make its results sufficiently indicative with the lack of a broader evidence. More importantly, the research has not provided enough interpretation for the recorded UMI Walkscores.

To achieve the research objective of assessing the impact of urban morphology compactness on UMI Walkscore of the recent designs of Emirati neighborhoods, and interpreting the impact of the macroscale Walkability indicators on the recorded scores, the research poses three main questions as follows:

1- What are the customized UMI Walkscore variables for the case of the Emirati neighborhoods.

2- What are the UMI Walkscore results, in comparison to Walkscores benchmarking, for the recent designs of the denser and more compact Emirati neighborhoods, especially when compared to the conventional urban sprawling model? 
3- How do the walkability macroscale measures of both urban morphology and urban planning affect the obtained UMI Walkscores for the assessed neighborhoods? The design's urban morphological measures are related mainly to pedestrian mobility network including FAR, Block Length, Street Connection Density, and Link-to-nodes ratio. The macroscale urban planning measures include related landuse indicators of the types and numbers of provided amenities, their locational distribution, Destination and Global Weights, as per the UMI Walkscore plugin.

Answering the research questions will help bridge the current gaps through perceiving the impacts that the macroscale indicators might have on walkability attainment/impediment in all the recent denser and more compact urban form deigns in Abu Dhabi and Dubai Emirates where they are being mostly developed. Also, this would lead to the readjustment of the macroscale indicators, while still in the design phase to enhance walkability in urban neighborhoods in the UAE and maybe other similar urban contexts in the region, to positively contribute to the attainment of their sustainability goals. While the research outcomes are expected to provide good qualitative assessment through the calculated UMI Walkscores that takes into consideration essential macroscale walkability indicators, it is worth mentioning that the research did not investigate other possible macroscale walkability measures that might be missed from the UMI Walkscore tool's variables. In addition, with its focus on walkability macroscale measures, the microscale fine-grain urban design measures, albeit very important, is not discussed here as they are outside the scope of this research and deserve their own dedicated investigations in further research.

\section{Research method and tools}

To meet the research objective and to answer its three posed questions, a quantitative case study method with multi-tools was utilized. But before applying the UMI Walkscore simulation on the case studies of the recent denser and more compact Emirati neighborhoods designs and comparing the recorded scores with a model design for a conventional urban sprawling neighborhood, the UMI Walkscore variables should be customized to be proper for these UAE neighborhoods' context. First, to customize the UMI Walkscore variables of the types of provided amenities on the neighborhood level, their prospective catchment distances, and their Destination and Global Weights, the locally developed guidelines and regulations for urban neighborhoods in Abu Dhabi and Dubai Emirates were carefully reviewed for developing a set of these UMI Walkscore customized variables. Other Emirates are usually following these guidelines as they lack their own ones, so far. These guidelines were developed by the concerned urban development authorities in the two Emirates. In Abu Dhabi, most of the walkability related guidelines were issued by Abu Dhabi Urban Planning Council (ADUPC) and are included in Abu Dhabi Community Facility Planning Standards Report (Abu Dhabi Urban Planning Council 2014a) and Abu Dhabi Public Realm Design Manual (Abu Dhabi Urban Planning Council 2014b). In addition, Abu Dhabi Housing Authority (2016) issued Abu Dhabi National Housing Guidelines for Integrated Communities. Meanwhile, the Community Facilities Standards issued by the Planning Department (2018) was the main document developed for this purpose in Dubai.

According to Abu Dhabi's Standards and Guidelines, the community facilities are linked with a corresponding community facilities hierarchy level (Fig. 1). So, for neighborhoods of 2000 residents or below no community facilities are required! But, for neighborhood populations between 2000 and 5999 residents, 'Per Capita' approach is recommended to calculate the number of schoolchildren and to determine which community facilities must be provided. For example, $1 \mathrm{KG}+$ Primary School (Educational Cycle 1) is needed for $14.9 \%$ of the population (1200 students), one Intermediate School (Educational Cycle 2) is needed for $6.9 \%$ of the population (1200 students), and one Secondary School (Educational Cycle 3) is needed for $5.5 \%$ of the population (1200 students). So, based on the population numbers, the type and numbers of amenities should be decided on the neighborhood, district, and sub-regional levels. Meanwhile, for neighborhoods with 6000-10,000 residents, community facilities should be provided at the Neighborhood Centre besides the Non-center community facilities (Fig. 1). The Neighborhood Center is assumed to serve the basic day-to-day needs of a community for religious, convenience retail and recreational services. The required facilities include community support center, health clinic, nursery, and community police point. Non-center community facilities must be provided but do not need to be located within a specific center. Non-center facilities have different thresholds for provision compared to the set population levels in the Neighborhood, District and Sub-regional Centers. For example, the provision of schools is based upon the number of schoolchildren in a neighborhood development proposal while a hospital, a police station, a petrol station is required on a District or a Sub-regional level depending on the number of residents. The standards table in Fig. 1 also incorporates, at the end, Optional Facilities that can be provided depending upon the outcomes defined by the master planner or 


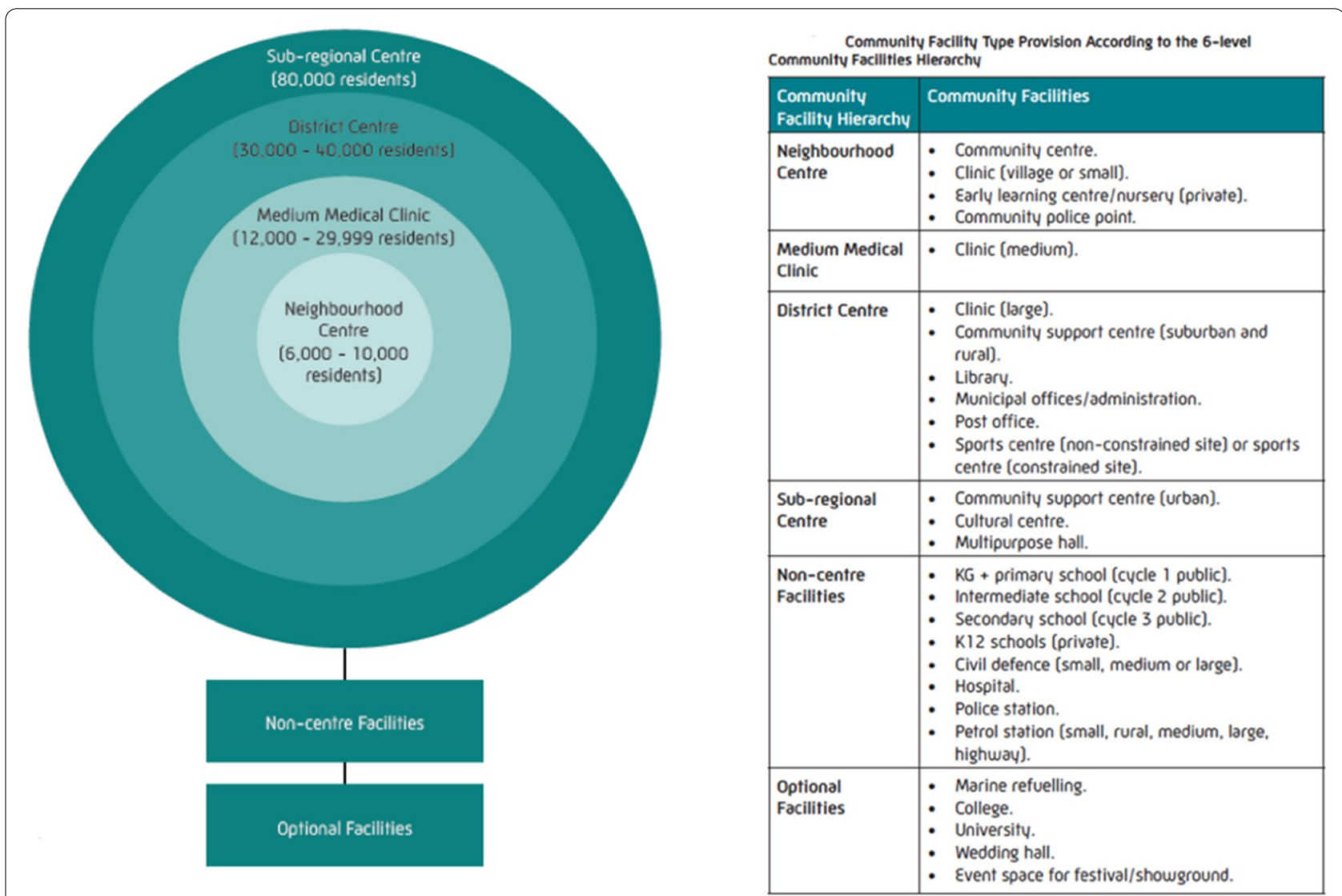

Fig. 1 Community amenities hierarchy guidelines in Abu Dhabi ( Source: Abu Dhabi Urban Planning Council 2014a)

developer. As for catchment distances, according to Abu Dhabi Community Facility Planning Standards, there is a need to provide Neighborhood Centers within a maximum $700 \mathrm{~m}$ walk of all residents (Fig. 2). Meanwhile, the appropriate catchment distance to neighborhood facilities is defined by $350 \mathrm{~m}$ in the Abu Dhabi National Housing Guidelines for Integrated Communities (Fig. 3) (Abu Dhabi Housing Authority 2016).

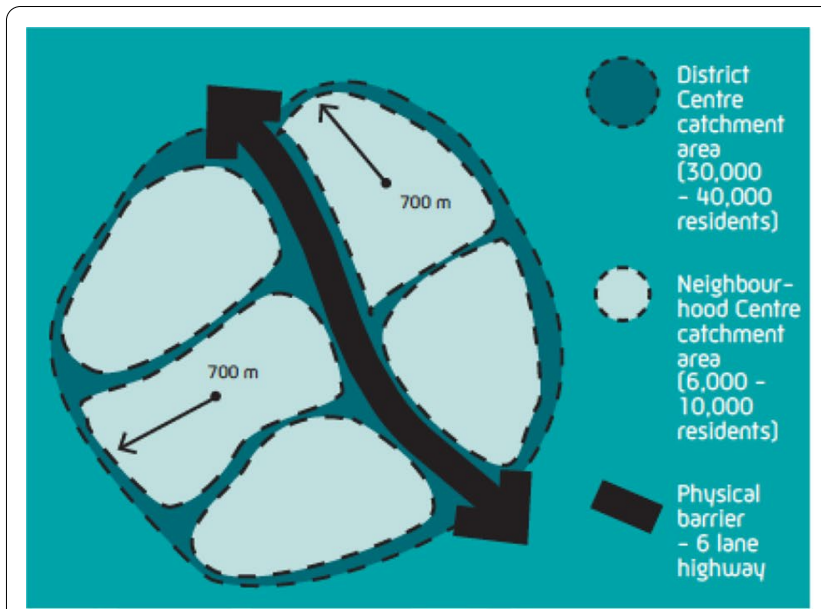

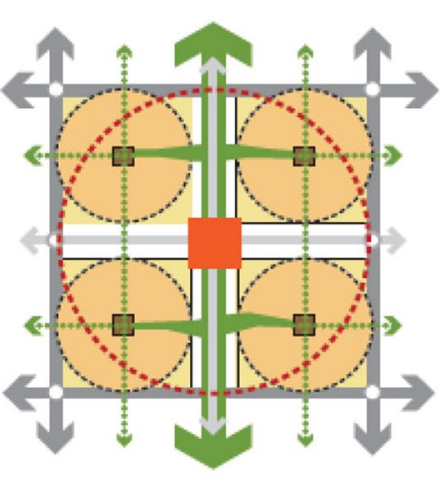

Figure 10.2: Indicative District Centre.

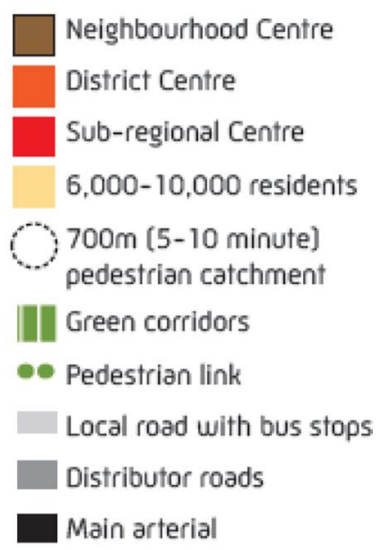

Fig. 2 Catchment distance for neighborhood centers in Abu Dhabi Community Facility Planning Standards ( Source: Abu Dhabi Urban Planning Council 2014a) 


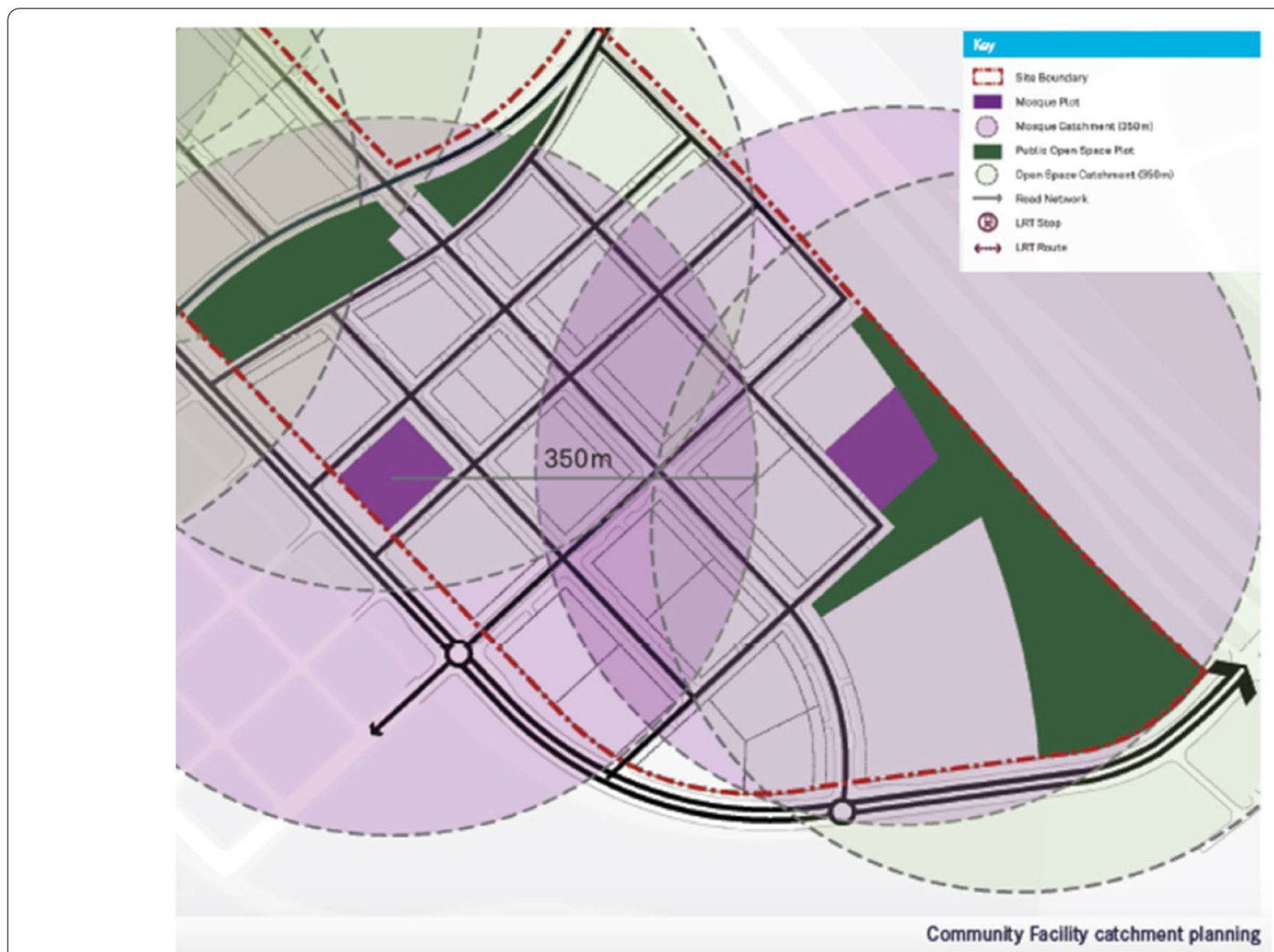

Fig. 3 Catchment distance for neighborhood facilities in Abu Dhabi National Housing Guidelines for Integrated Communities ( Source: Abu Dhabi Housing Authority 2016)

In Dubai Emirate, there is a significantly different approach for the regulations of amenities and catchment distances. First, there are two categories of development, the Neighborhood Level (from 2000 to 6000 residents) and the Region/District Level (from 6000 to 12,000 residents). In each of these two categories, there are three classifications based on the population density (Appendix Table 7). The first is dedicated to low population density of less than 70 person per hectare (pph), the second is for population densities ranging between 70 and $220 \mathrm{pph}$, and the third is for those above $220 \mathrm{pph}$. The types of the provided amenities are fixed for these classifications in each category, but they are just different in numbers and catchment distances that range between 400 and $1000 \mathrm{~m}$ for the first density classification, from 350 to $1000 \mathrm{~m}$ for the second category, and from 300 to $1000 \mathrm{~m}$ for the third one. Also, the provision of all amenities is mandatory except for the Children Play Zone in the first category (Neighborhood Level) and for Public Plaza in the second category (Region/District Level) (Appendix Table 7).
Apparently, the current guidelines and regulations in both Abu Dhabi and Dubai Emirates have significant differences, in a way that made it difficult to initiate a customized list of amenities and their related catchment distances based on them alone. Instead, the landuse plans of the investigated neighborhoods, as detailed later, were consulted to bridge this wide gap, especially in terms of the types and numbers of amenities. The same approach was adopted for defining the 'minimum' required numbers of each type of the defined amenities and their appropriate catchment distances. Ultimately, as shown in Table 1, the customized list of the amenities' types, minimum required numbers, and maximum catchment distances were developed, with some obvious inevitable subjectivity. The suggested catchment distances to the defined amenities ranged between 350 and $800 \mathrm{~m}$, i.e., from about 5 to $10 \mathrm{~min}$ ' walk. These are close, as much as possible, to both the locally and internationally recognized catchment distances, as discussed above.

After defining the types and minimum number of required amenities, and their related catchment 
Table 1 Customized types and numbers of amenities, and their catchment distances for Emirati neighborhoods

\begin{tabular}{llll}
\hline & Type & $\begin{array}{l}\text { (Minimum) } \\
\text { needed number }\end{array}$ & $\begin{array}{l}\text { Maximum } \\
\text { catchment } \\
\text { distances }(\mathbf{m})\end{array}$ \\
\hline 1 & Cafeteria & 5 & 800 \\
2 & Grocery & 3 & 600 \\
3 & Pharmacy & 1 & 800 \\
4 & Retail & 5 & 800 \\
5 & Primary school & 1 & 800 \\
6 & Kindergarten & 2 & 350 \\
7 & Mosque & 1 & 800 \\
8 & Clinic & 1 & 800 \\
9 & Green spaces & 1 & 800 \\
10 & All others & 1 & 800 \\
\hline
\end{tabular}

Table 2 Weighted amenities in the studied neighborhoods

\begin{tabular}{llll}
\hline & Type & Global weight & $\begin{array}{l}\text { Destination/ } \\
\text { local weight }\end{array}$ \\
\hline 1 & Cafeteria & 3 & $10,8,6,4,2$ \\
2 & Grocery & 3 & $5,3,1$ \\
3 & Pharmacy & 3 & 1 \\
4 & Retail & 2 & $10,8,6,4,2$ \\
5 & Primary school & 2 & 1 \\
6 & Kindergarten & 3 & 5,3 \\
7 & Mosque & 3 & 1 \\
8 & Clinic & 1 & 1 \\
9 & Green spaces & 2 & 1 \\
10 & All others & 1 & 1 \\
\hline
\end{tabular}

distances, the Global Weights and the Destination Weights of each amenity's type were defined and customized in the UMI's plugin. With the lack of any other reliable resource, the Global Weighting measures were mainly defined based on the results of brief consulting interviews with 6 urban planning experts and researchers at the United Arab Emirates University. The interviewed planning experts were selected based on their prior experience in neighborhood planning in the UAE. They were simply asked about the "degree of importance" of each of the types of the defined amenities, which was interpreted into Global Weights. As a result, the Mosque, Grocery, Kindergarten, Restaurant/Cafe Shop, and Pharmacy came first with a Global Weight of 3, followed by the Neighborhood Park, School and Convivence Retail with a Global Weight of 2. lastly came the Clinic and other types of amenities, if any, with a Global Weight of 1 . Meanwhile, Destination Weights were rationally defined as per the numbers of each type of the amenities (Table 2).
After defining the customized types and numbers of local amenities, their catchment distances, and their Global and Destination Weights, digital models for the amenities' buildings and lots, houses, and the overall neighborhoods plots were developed showing the plots boundaries and the open space/street grid of each case study. To facilitate the UMI Walkscore simulations, the pedestrian mobility networks was drawn, while each amenity was accurately located, and the customized amenities' values were uploaded as identified in Tables 1 , 2. After undertaking all the pre-simulation steps, the walkability computational simulations were conducted.

The case study quantitative method in which a conventional model design of an urban sprawling neighborhood (Al Dhaher neighborhood in Al Ain city (N1), Abu Dhabi Emirate) and the six recent claimed to be 'sustainable' designs of Emirati citizens neighborhoods, with their varying but denser and more compact urban morphologies, were analyzed. The selected neighborhoods designs are showcasing the recent design trend in Abu Dhabi and Dubai Emirates, where the urban sustainability initiatives are more prominent, if compared with other UAE's Emirates. They are Al Falah South (N2), Al Falah North (N3), and Watani 1 (N7) in Abu Dhabi city; Al Ghreiba (N4) and Shubat Al Woutah (N6) in Al Ain city; and Oud Al Muteena (N5) in Dubai. Figure 4 illustrates the geographical locations for these neighborhoods.

Al Dhaher neighborhood in Al Ain is selected as an obvious design model of the conventional sprawling urban form and low population density designs that were frequently developed in the UAE since the 1970s until almost the mid-2000s where such urban sprawls were slowly replaced by more compact and denser urban forms (Khaled 2020) (Fig. 5). Al Dhaher was designed in 2002 on a rectangular-shape lot with an area of about 285 hectares (ha). The areas of the neighborhood's 460 twostory detached houses plots ranged between $45 \times 60 \mathrm{~m}$ and $45 \times 45 \mathrm{~m}$. The estimated accommodated total population is 3312 persons with a gross population density of as low as $11.02 \mathrm{pph}$. In the design, the housing plots are arranged in clusters of various numbers range from 10 to 16 plots congregated around communal open spaces. The main 'gradually' provided amenities are 9 mosques, 2 schools, a clinic, and retail shops located on both the longitudinal axial spine of the neighborhood and on its outer fringes.

Meanwhile, the designs of the six recent neighborhoods have been claimed to be sustainable with a main difference form the conventional urban sprawling model in having more compact urban forms and higher population density. Table 3 summarizes the background information and the urban characteristics of the designs of these neighborhoods including their land-use plans, numbers, 


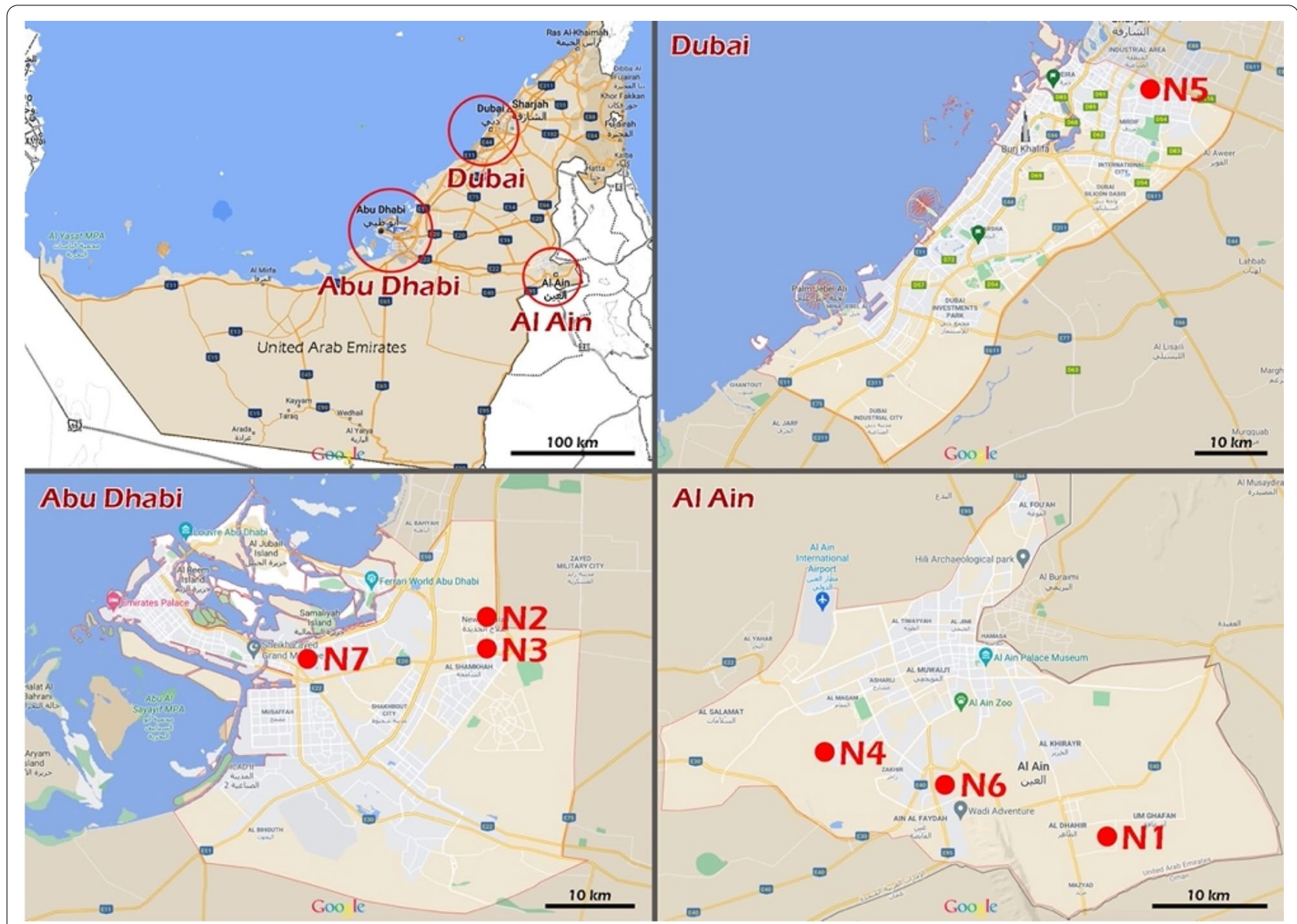

Fig. 4 The geographical locations of the case studies neighborhoods in Al Ain, Abu Dhabi and Dubai Cities, UAE

areas and types of dwellings, number of population and population densities, types and numbers of provided amenities and their locational distribution patterns. The degree of urban compactness and density of the studied neighborhoods were analyzed through defining both the morphological characteristics including FAR, Street Intersection Density, Link-to-nodes ratio, as well as the expected gross population density calculated by dividing the total development area in ha over the expected number of population. The FAR was calculated for each studied neighborhoods through the UMI plugin software and the block lengths were mainly measured form the design drawings. Meanwhile, the street connectivity, was figured out through calculating two measures using simple formulas. First, is the Street Intersection Density of the street/pedestrian networks where the intersection density equaled the total number of street intersections (including dead ends) divided by the total neighborhood area in square kilometers. Second, is the Link-to-nodes ratio which equals the total number of road segments between intersections divided by the total number of intersections including dead ends. Normally, the Street Intersection Density is utilized as a measure of network compactness, while the Link-to-nodes ratio is considered as a measure of network connectivity. But in practice, the Street Intersection Density is often used for measuring street network connectivity as well. It is maintained that in most cases, but not always, a high Street Intersection Density corresponds to a more walkable neighborhood as it indicates high accessibility to destinations (EnviroAtlas 2019). Moreover, a Link-to-nodes ratio of 1.40 or higher is usually used as the threshold of high street connectivity (CNU 2019).

After accomplishing the above-mentioned steps, the UMI Walkscore simulation was performed on all the analyzed cases and were compared to the established benchmark for this score. Lastly, the analysis of the impact of the walkability macroscale morphological and urban planning measures on the obtained UMI Walkscores was performed. The analyzed morphological measures included the calculated FARs, Street Intersection Density, Link-to-nodes ratio, and expected population 


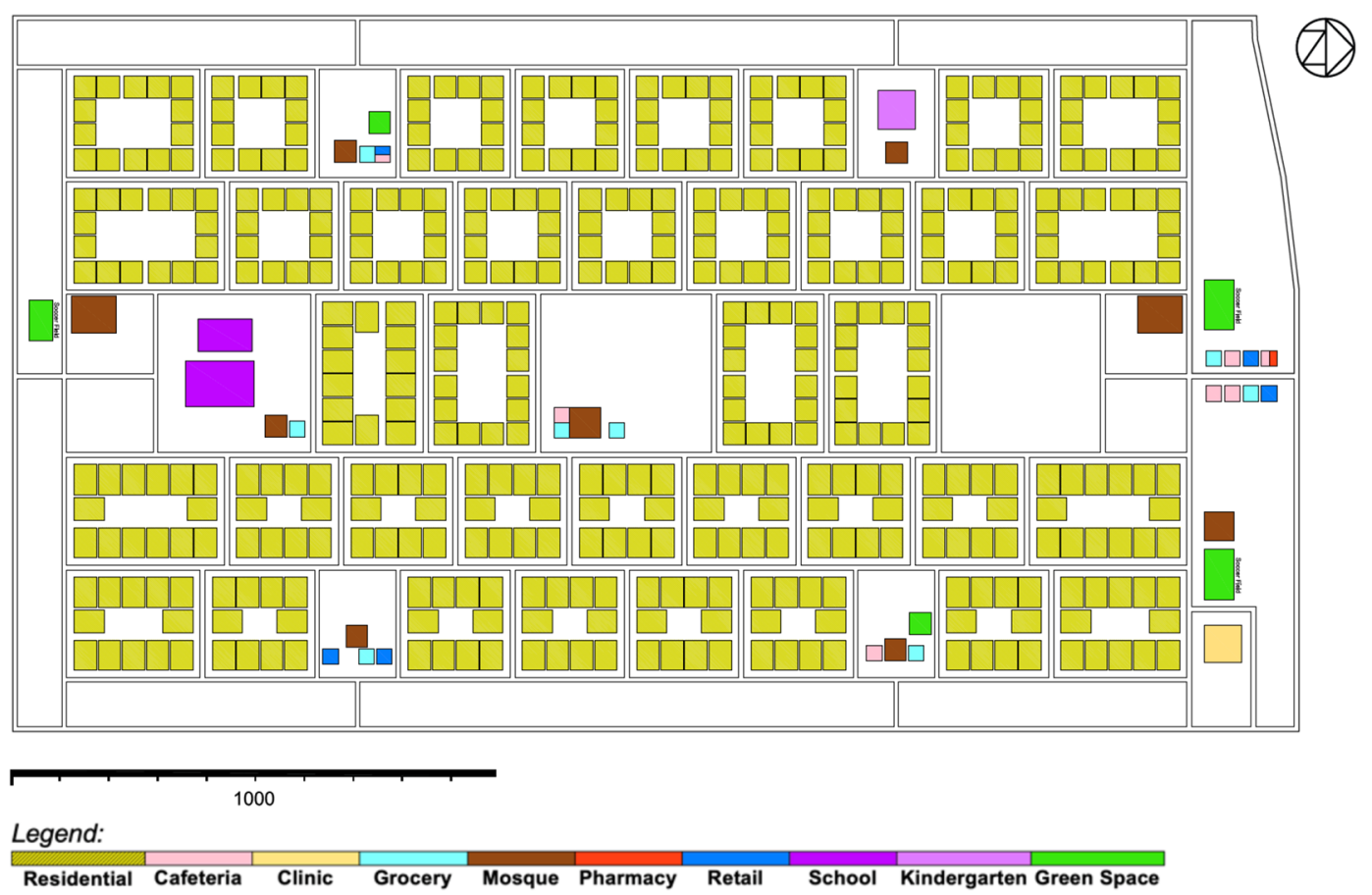

Fig. 5 Neighborhood N1: Al Dhaher, representing the sprawling urban morphology in the UAE

density. Meanwhile, the analyzed macroscale urban planning measures included both the explicit indicators of the land-use (Types and Numbers of amenities, their locational distribution and catchment distances) and the Implicit indicators of the Global and Destination weights. The results of these simulations as presented in the following sections.

\section{Results}

Macroscale urban morphology indicators for the assessed neighborhoods

As shown in Table 4, the experienced significant changes in the walkability macroscale morphological measures in the recent more compact and denser neighborhoods designs, if compared with the conventional urban sprawling neighborhood model (N1), could be represented in, first, the increased population density from $11.02 \mathrm{pph}$ in the $\mathrm{N} 1$ to as maximum as $48.34 \mathrm{pph}$ in the N7 case. The only exception was in $\mathrm{N} 2$ neighborhood with only $10.51 \mathrm{pph}$. Second, is the increased values of both the FAR and street network connectivity, though not consistent in all cases. The maximum FAR and Street Intersection Density values were noticed in N7 which reached to 0.41 and 197.22/ $\mathrm{km}^{2}$ respectively, compared with only 0.11 and 40.20 / $\mathrm{km}^{2}$ in the $\mathrm{N} 1$ urban sprawling $\mathrm{N} 1$ case. One exception again is N2, which despite having bigger FAR value of
0.18 than N1 but has slightly less value for the Street Intersection Density of $39.78 / \mathrm{km}^{2}$ than N1. The Linkto-nodes ratios have not changed significantly in the new neighborhoods' designs, while the Block Lengths have partially decreased in all recent cases if compared to N1 neighborhood, except in N2, as well.

So, all in all, for all recent neighborhoods designs the increase of population density and urban morphology compactness (represented in the FARs and the Street Intersection Density), was noticeably significant with only one exception of N2, if compared with the earlier generation of conventionally designed neighborhoods in the UAE, such as Al Dhaher neighborhood. But, although all neighborhoods are allocated for Emirati citizens in a form of single-family housing, the population density and the degree of both compactness of these recent neighborhoods' designs were also inconsistent and widely varied among the studied six cases. A big difference was noticed as well in the form of the street/pedestrian networks that varied among orthogonal grid, curvilinear grid, and a mixture of both. This has been reflected on the calculated street connectivity measures including Intersection Density and the Link-to-nodes ratio. Meanwhile, little change was evident in the provided types of amenities in the new recent designs compared to the conventional case. Still, the densification of amenities was inconsistently varying among the studied cases, except the green open spaces 
Table 3 The land-uses and urban characteristics of the selected case studies

\begin{tabular}{|c|c|c|}
\hline $\begin{array}{l}\text { Case } \\
\text { Study }\end{array}$ & Background Information & Land-Use Plans \\
\hline 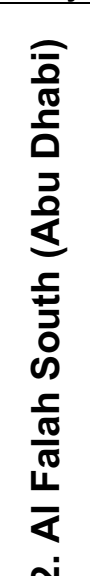 & $\begin{array}{l}\text { Purpose: Social Housing Project for } \\
\text { Citizens } \\
\text { Developer: Abu Dhabi Municipality } \\
\text { Completed: } 2005 \\
\text { Total Number of Houses: } 785 \\
\text { Total Area: } 538 \text { Hectares } \\
\text { Total Population: } 5,652 \text { Person } \\
\text { Gross Population Density: } 10.51 \text { pph } \\
\text { Housing Type: G+1 Single Family House } \\
\text { Plot Sizes: } 45 \times 45 \mathrm{~m} \mathrm{\&} 45 \times 60 \mathrm{~m} \\
\text { Housing Sizes: } 963 \mathrm{~m}^{2} \& 1181 \mathrm{~m}^{2} \\
\text { Plot Arrangements: Back-to-Back } \\
\text { Amenities: } 14 \text { Cafeteria, } 12 \text { Grocery, } 1 \\
\text { Pharmacy, } 9 \text { Retail Units, } 4 \text { School, } 3 \\
\text { Kindergarten, } 11 \text { Mosque, } 0 \text { Clinic, } 14 \text { Green } \\
\text { Space. }\end{array}$ & \\
\hline 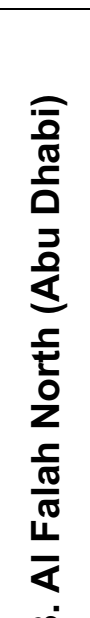 & $\begin{array}{l}\text { Purpose: Social Housing Project for } \\
\text { Citizens } \\
\text { Developer: Abu Dhabi Municipality } \\
\text { Construction Started: } 2009 \text {, and first } \\
\text { hand-over in } 2012 \text {. } \\
\text { Total Number of Houses: } 1010 \\
\text { Total Area: } 352 \text { Hectares } \\
\text { Total Population: } 7,272 \text { Person } \\
\text { Gross Population Density: } 20.66 \text { pph } \\
\text { Housing Type: G+1 Single Family House } \\
\text { Plot Sizes: } 30 \times 32 \mathrm{~m} / 30 \times 45 \mathrm{~m} \\
\text { Housing Sizes: } 477 \mathrm{~m}^{2} / 501 \mathrm{~m}^{2} / 582 \mathrm{~m}^{2} \\
\text { Plot Arrangements: Back-to-Back. } \\
\text { Number of Amenities: } 3 \text { Cafeteria, } 4 \\
\text { Grocery, } 2 \text { Pharmacy, } 3 \text { Retail Units, } 2 \\
\text { School, } 1 \text { Kindergarten, } 5 \text { Mosque, } 1 \text { Clinic, } \\
13 \text { Green Space. }\end{array}$ & \\
\hline 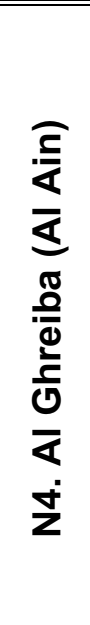 & $\begin{array}{l}\text { Purpose: Social Housing Project for } \\
\text { Citizens } \\
\text { Developer: Abu Dhabi Municipality } \\
\text { Completed: } 2014 \\
\text { Total Number of Houses: } 636 \\
\text { Total Area: } 140 \text { Hectares } \\
\text { Total Population: } 4,579 \text { Person } \\
\text { Gross Population Density: } 32.72 \mathrm{pph} \\
\text { Housing Type: G+1 Single Family House } \\
\text { Plot Sizes: } 30 \times 36 \mathrm{~m} \\
\text { Housing Sizes: } 420 \mathrm{~m}^{2} \text { / } 500 \mathrm{~m}^{2} \\
\text { Plot Arrangements: Back-to-Back and } \\
\text { Clustering around Pocket Parks. } \\
\text { Amenities: } 3 \text { Cafeteria, } 4 \text { Grocery, } 1 \\
\text { Pharmacy, } 2 \text { Retail Units, } 1 \text { School, } 1 \\
\text { Kindergarten, } 2 \text { Mosque, } 0 \text { Clinic, } 45 \text { Green } \\
\text { Space. }\end{array}$ & \\
\hline
\end{tabular}


Table 3 (continued)

\begin{tabular}{|c|c|c|}
\hline 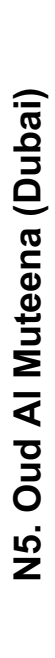 & $\begin{array}{l}\text { Purpose: Social Housing Project for } \\
\text { Citizens } \\
\text { Developer: Muhammed Bin Rashid } \\
\text { Housing Establishment } \\
\text { Completed: } 2016 \\
\text { Total Number of Houses: } 1,596 \\
\text { Total Area: } 239 \text { Hectares } \\
\text { Total Population: } 11,491 \text { Person } \\
\text { Gross Population Density: } 48.11 \text { pph } \\
\text { Housing Type: G+1 Single Family House } \\
\text { and G+1 Town Houses } \\
\text { Plot Sizes: } 25 \times 30 \mathrm{~m} / 25 \times 35 \mathrm{~m} \\
\text { Town House: } 12 \times 14 \mathrm{~m} \\
\text { Housing Sizes: } 309 \mathrm{~m}^{2} / 445 \mathrm{~m}^{2} / 554 \mathrm{~m}^{2} \\
\text { Town House: } 203 \text { m² } 337 \text { m² } \\
\text { Plot Arrangements: Back-to-Back } \\
\text { Amenities: } 2 \text { Cafeteria, } 5 \text { Grocery, } 0 \\
\text { Pharmacy, } 1 \text { Retail Unit, } 0 \text { School, } 1 \\
\text { Kindergarten, } 5 \text { Mosque, } 0 \text { Clinic, } 5 \text { Green } \\
\text { Space. }\end{array}$ & AEA $=E$ \\
\hline 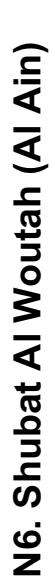 & $\begin{array}{l}\text { Purpose: Social Housing Project for } \\
\text { Citizens } \\
\text { Developer: Al Ain Municipality } \\
\text { Construction Started: } 2011 \text {, Infrastructure } \\
\text { completed in: } 2016 \\
\text { Total Number of Houses: } 1,647 \\
\text { Total Area: } 465 \text { Hectares } \\
\text { Total Population: } 12,188 \text { Person } \\
\text { Gross Population Density: } 26.20 \text { pph } \\
\text { Housing Type: G+1 Single Family House } \\
\text { Plot Sizes: } 30 \text { x } 36 \\
\text { Housing Sizes: } 952 \text { m² / } 1012 \text { m² }^{2} \\
\text { Plot Arrangements: Back-to-Back } \\
\text { Amenities: } 3 \text { Cafeteria, } 3 \text { Grocery, } 1 \\
\text { Pharmacy, } 2 \text { Retail, } 2 \text { School, } 1 \\
\text { Kindergarten, } 8 \text { Mosque, } 0 \text { Clinic, } 9 \text { Green } \\
\text { Space. }\end{array}$ & 4 \\
\hline 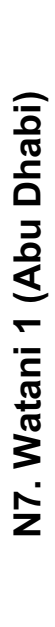 & $\begin{array}{l}\text { Purpose: Social Housing Project for } \\
\text { Citizens } \\
\text { Developer: Abu Dhabi Municipality } \\
\text { Completed: } 2015 \\
\text { Total Number of Houses: } 968 \\
\text { Total Area: } 144 \text { Hectares } \\
\text { Total Population: } 6,970 \text { Person } \\
\text { Gross Population Density: } 48.34 \text { pph } \\
\text { Housing Type: Semi-Detached G+1 } \\
\quad \text { Single Family House } \\
\text { Plot Sizes: } 25 \times 28 \mathrm{~m} / 20 \times 25 \mathrm{~m} \\
\text { Housing Sizes: } 395 \text { m² / } 512 \text { m² / } 611 \mathrm{~m}^{2} \\
\text { Plot Arrangements: Back-to-Back and } \\
\text { Clustering around Communal Open } \\
\text { Spaces. } \\
\text { Amenities: } 2 \text { Cafeteria, } 3 \text { Grocery, } 1 \\
\text { Pharmacy, } 1 \text { Retail, } 1 \text { School, } 1 \\
\text { Kindergarten, } 1 \text { Mosque, } 0 \text { Clinic, } 44 \text { Green } \\
\text { Space. }\end{array}$ & 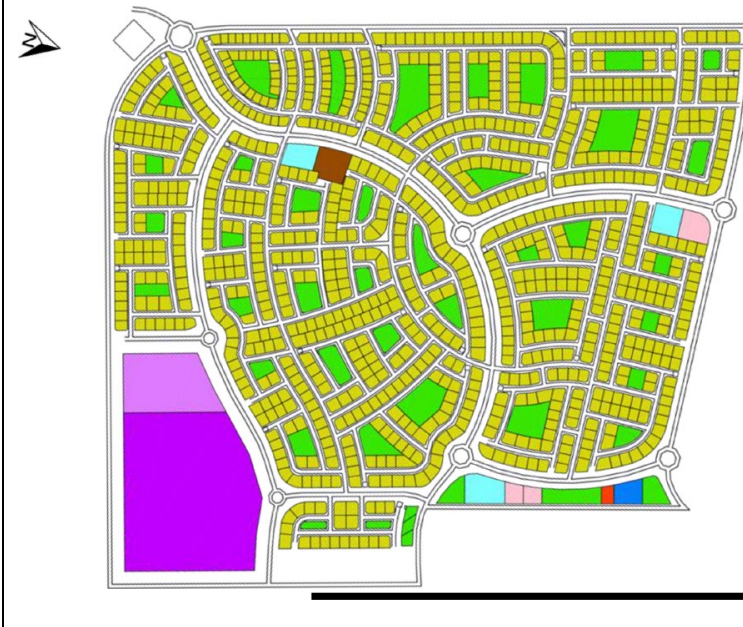 \\
\hline
\end{tabular}

Legend:

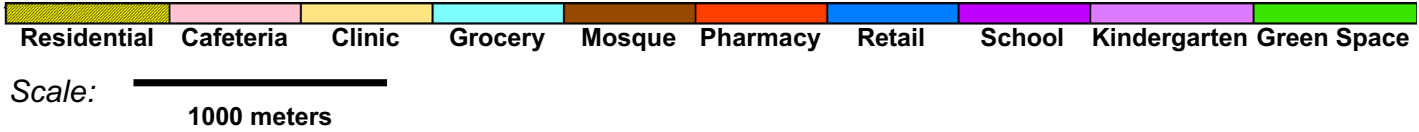


Table 4 Summary of the macroscale urban morphological indicators of the studied neighborhoods

\begin{tabular}{|c|c|c|c|c|c|c|c|c|}
\hline Neighbor & Total area (ha) & $\begin{array}{l}\text { Total } \\
\text { population } \\
\text { (p) }\end{array}$ & $\begin{array}{l}\text { Population } \\
\text { density (pph) }\end{array}$ & $\begin{array}{l}\text { Floor area } \\
\text { ratio (FAR) }\end{array}$ & $\begin{array}{l}\text { Designed types } \\
\text { and no. of } \\
\text { amenities }\end{array}$ & Block length & $\begin{array}{l}\text { Street } \\
\text { intersection } \\
\text { density }\end{array}$ & $\begin{array}{l}\text { Link-to- } \\
\text { nodes } \\
\text { ratio }\end{array}$ \\
\hline \multicolumn{9}{|c|}{ Urban sprawling case } \\
\hline \multirow[t]{9}{*}{$\mathrm{N} 1$} & 301 & 3312 & 11.02 & 0.11 & Cafeteria (7) & $180,270 \mathrm{~m}$ & $40.20 / \mathrm{km}^{2}$ & 1.496 \\
\hline & & & & & Grocery (8) & & & \\
\hline & & & & & Pharmacy (1) & & & \\
\hline & & & & & Retail (5) & & & \\
\hline & & & & & School (1) & & & \\
\hline & & & & & Kindergarten (1) & & & \\
\hline & & & & & Mosque (9) & & & \\
\hline & & & & & Clinic (1) & & & \\
\hline & & & & & Green Space (5) & & & \\
\hline \multicolumn{9}{|c|}{ Urban compact cases } \\
\hline \multirow[t]{9}{*}{ N2 } & 538 & 5652 & 10.51 & 0.18 & Cafeteria (14) & $350,560 \mathrm{~m}$ & $39.78 / \mathrm{km}^{2}$ & 1.491 \\
\hline & & & & & Grocery (12) & & & \\
\hline & & & & & Pharmacy (1) & & & \\
\hline & & & & & Retail (9) & & & \\
\hline & & & & & School (4) & & & \\
\hline & & & & & Kindergarten (3) & & & \\
\hline & & & & & Mosque (11) & & & \\
\hline & & & & & Clinic (0) & & & \\
\hline & & & & & Green Space (14) & & & \\
\hline \multirow[t]{9}{*}{ N3 } & 352 & 7272 & 20.66 & 0.18 & Cafeteria (3) & $150,180,240,270 \mathrm{~m}$ & $59.38 / \mathrm{km}^{2}$ & 1.498 \\
\hline & & & & & Grocery (4) & & & \\
\hline & & & & & Pharmacy (2) & & & \\
\hline & & & & & Retail (3) & & & \\
\hline & & & & & School (2) & & & \\
\hline & & & & & Kindergarten (1) & & & \\
\hline & & & & & Mosque (5) & & & \\
\hline & & & & & Clinic (1) & & & \\
\hline & & & & & Green Space (13) & & & \\
\hline \multirow[t]{9}{*}{ N4 } & 140 & 4579 & 32.72 & 0.26 & Cafeteria (3) & $90,120,150 \mathrm{~m}$ & $126.43 / \mathrm{km}^{2}$ & 1.424 \\
\hline & & & & & Grocery (4) & & & \\
\hline & & & & & Pharmacy (1) & & & \\
\hline & & & & & Retail (2) & & & \\
\hline & & & & & School (1) & & & \\
\hline & & & & & Kindergarten (1) & & & \\
\hline & & & & & Mosque (2) & & & \\
\hline & & & & & Clinic (0) & & & \\
\hline & & & & & Green Space (45) & & & \\
\hline \multirow[t]{9}{*}{ N5 } & 239 & 11,491 & 48.11 & 0.26 & Cafeteria (2) & $250,275 \mathrm{~m}$ & $89.12 / \mathrm{km}^{2}$ & 1.319 \\
\hline & & & & & Grocery (5) & & & \\
\hline & & & & & Pharmacy (0) & & & \\
\hline & & & & & Retail (1) & & & \\
\hline & & & & & School (0) & & & \\
\hline & & & & & Kindergarten (1) & & & \\
\hline & & & & & Mosque (5) & & & \\
\hline & & & & & Clinic (0) & & & \\
\hline & & & & & Green Space (5) & & & \\
\hline
\end{tabular}


Table 4 (continued)

\begin{tabular}{|c|c|c|c|c|c|c|c|c|}
\hline Neighbor & Total area (ha) & $\begin{array}{l}\text { Total } \\
\text { population } \\
\text { (p) }\end{array}$ & $\begin{array}{l}\text { Population } \\
\text { density (pph) }\end{array}$ & $\begin{array}{l}\text { Floor area } \\
\text { ratio (FAR) }\end{array}$ & $\begin{array}{l}\text { Designed types } \\
\text { and no. of } \\
\text { amenities }\end{array}$ & Block length & $\begin{array}{l}\text { Street } \\
\text { intersection } \\
\text { density }\end{array}$ & $\begin{array}{l}\text { Link-to- } \\
\text { nodes } \\
\text { ratio }\end{array}$ \\
\hline \multirow[t]{9}{*}{ N6 } & 465 & 12,188 & 26.20 & 0.38 & Cafeteria (3) & $150,180,240,300 \mathrm{~m}$ & $72.69 / \mathrm{km}^{2}$ & 1.435 \\
\hline & & & & & Grocery (3) & & & \\
\hline & & & & & Pharmacy (1) & & & \\
\hline & & & & & Retail (2) & & & \\
\hline & & & & & School (2) & & & \\
\hline & & & & & Kindergarten (1) & & & \\
\hline & & & & & Mosque (8) & & & \\
\hline & & & & & Clinic (0) & & & \\
\hline & & & & & Green Space (9) & & & \\
\hline \multirow[t]{9}{*}{ N7 } & 144 & 6970 & 48.34 & 0.41 & Cafeteria (2) & $150,175,250,300 \mathrm{~m}$ & $197.22 / \mathrm{km}^{2}$ & 1.359 \\
\hline & & & & & Grocery (3) & & & \\
\hline & & & & & Pharmacy (1) & & & \\
\hline & & & & & Retail (1) & & & \\
\hline & & & & & School (1) & & & \\
\hline & & & & & Kindergarten (1) & & & \\
\hline & & & & & Mosque (1) & & & \\
\hline & & & & & Clinic (0) & & & \\
\hline & & & & & Green Space (44) & & & \\
\hline
\end{tabular}

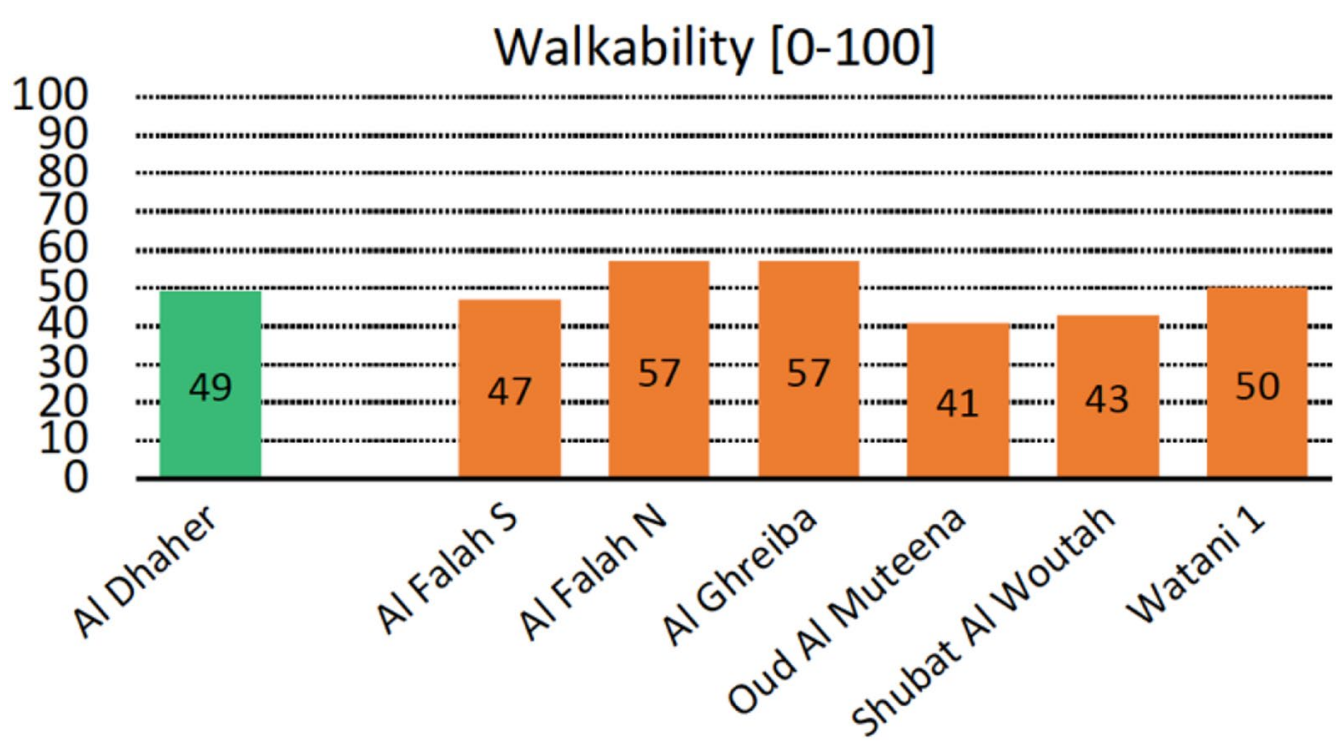

Conventional

New - Single Family House

Fig. 6 Comparing UMI Walkscores for the conventionally designed urban sprawling neighborhood-Al Dhaher (N1) vs the six denser and more compact case studies 


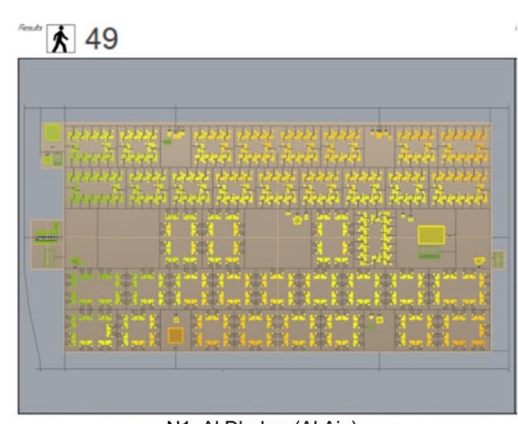

N1. Al Dhaher (Al Ain)

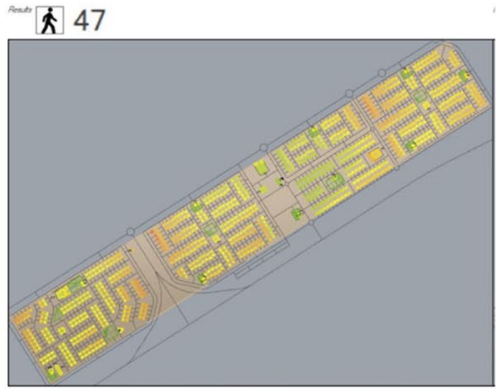

N2. Al Falah South (Abu Dhabi)

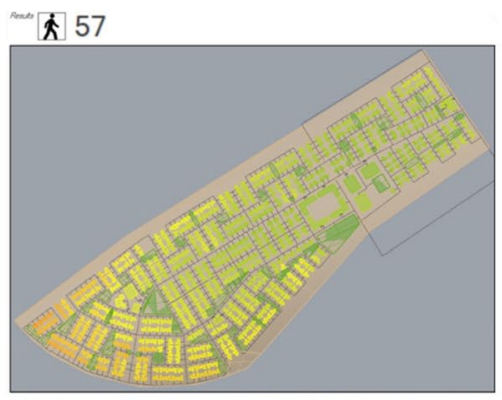

N4. Al Ghreiba (Al Ain, Abu Dhabi Emirate)

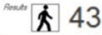

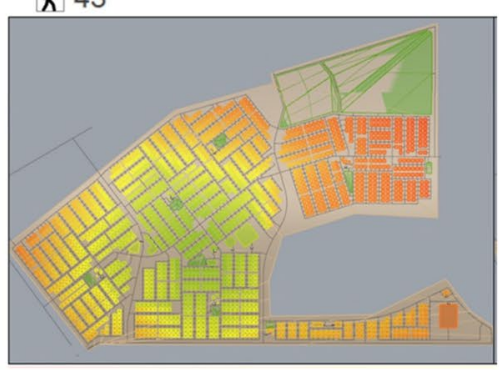

N6. Shubat Al Woutah (Al Ain, Abu Dhabi Emirate)

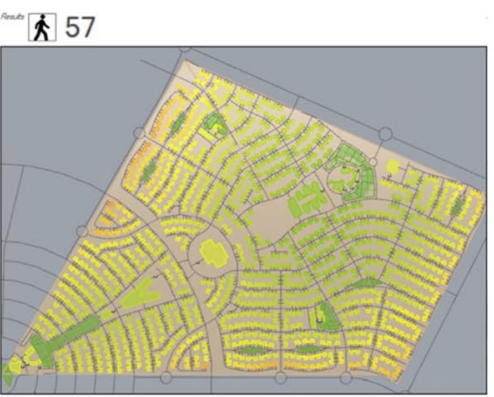

N3. Al Falah North (Abu Dhabi)

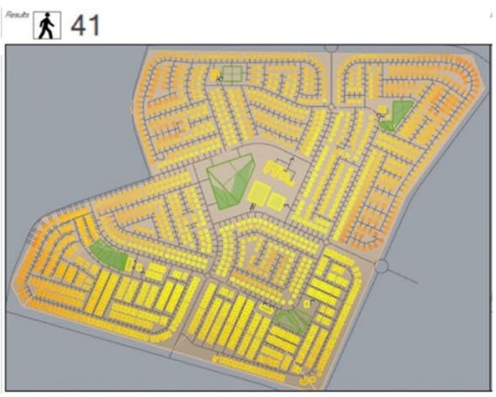

N5. Oud Al Muteena (Dubai)

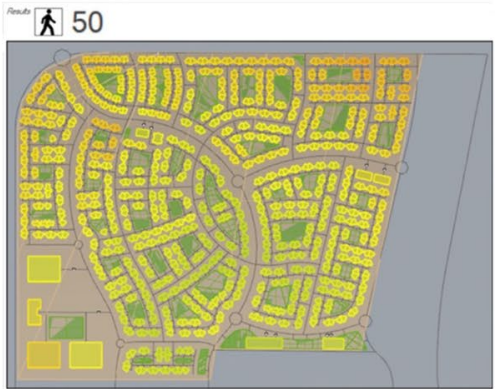

N7. Watani 1 (Abu Dhabi)

Fig. 7 Visual diagrams for the results of the computational simulations for the average UMI Walkscores for the urban sprawl (N1), and the urban compact case studies (N2-N7) (the greener the color, the better the score)

which were increased in most of the designs of the recent neighborhoods, especially in N7.

\section{Recorded UMI walkscores}

As shown in Fig. 6, the recorded UMI Walkscore for Al Dhaher neighborhood (N1), with its conventional urban sprawling form, reached 49. While this is indicating a 'Car-Dependent' neighborhood, it still touches the benchmark Walkscore of 50-69 for 'Somewhat Walkable' neighborhoods. In Fig. 7 that shows color coded results of the UMI Walkscore simulation for all studied neighborhoods (the greener the better score), it is shown that 
several houses in neighborhood N1, especially in the bottom section, are apparently getting lower Walkscores. Meanwhile, the UMI Walkscore simulation for the designs of the six denser and more compact case studies resulted in Walkscores ranging between 41 to 57 [41 Oud Al Muteena (N5), 43 Shubat Al Woutah (N6), 47 for Al Falah South (N2), 50 for Watani 1 (N7), and 57 for both of Al Falah North (N3) and Al Ghreiba (N4)].

The recorded scores indicate that three neighborhoods (N2, N5 and N6) are categorized as 'Car-Dependent' neighborhoods and the other three (N3, N4, and N7) are considered 'Somewhat Walkable' neighborhoods. As depicted in Fig. 7, several houses in all the six neighborhoods are considerably receiving low UMI Walkscores. This means that residents would be relying chiefly on their own cars in their mobility within their neighborhoods.

\section{Discussion}

While the correlation between the macroscale urban morphological and planning measures, on the one hand, and the UMI Walkscore results on the other hand, could be individually investigated for each neighborhood, still, it is believed that the comparison among all neighborhoods will give some overall insights about the effect of the designed urban form qualities, including those related to urban compactness, on the degree of achieving satisfactorily UMI Walkscores. In the following two sections the relationships between the obtained UMI Walkscore and the two sets of the walkability macroscale urban measures are discussed, to reveal the walkability macroscale measures that most affected the UMI Walkscores, thus, achieve the main research objective.

\section{Impacts of macroscale urban morphological indicators on UMI walkscore}

Table 5 illustrates the comparative correlations between the UMI Walkscore simulation results and the main urban morphology compactness indicators of the FAR and Street Connectivity (Street Intersection Density and Link-to-nodes ratio), for each of the designs of the studied neighborhood. It also presents the expected Gross Population Density in these designs.

It is unexpectedly divulged that the calculated UMI Walkscore in the urban sprawling case study of $\mathrm{Al}$ Dhaher (N1), despite its less dense/compact urban form, was slightly better, in average, than the cases of the denser and more compact urban forms of Al Falah South (N2), Oud Al Muteena (N5), and Shubat Al Woutah (N6). One would expect the results to be the opposite especially with the more compact urban forms that presumably would lead to more proximity of amenities and eventually more walkable neighborhoods, i.e. with higher UMI Walkscores. The design of Watani 1 Neighborhood (N7) with its highest estimated population density, and urban form compactness, resulting from the highest FAR (due to decreasing the housing plot sizes) and Street Connectivity measures, achieved a UMI Walkscore value of only 50, while the most urban sprawling neighborhood (N1) with its lowest population density and lowest urban form compactness with a FAR of only 0.11 and a Street Intersection Density of only 40.20 , achieved almost the same UMI Walkscore value (49). So, if the neighborhood with the best compact urban form (N7) is not performing as much better as the lowest compact urban sprawling case (N1), then the compact urban morphology indicators with the high FAR and Street Connectivity values are not sufficient macroscale factors leading to enhancing walkability.

For the walkability macroscale urban morphological measures per se, it seems that for the recent neighborhoods' designs little attention was paid to the significant effect of the two street network connectivity measures of Street Intersection Density and the Link-to-nodes ratio. For example, the calculated Street Intersection Density for N4 neighborhood was $126.429 / \mathrm{km}^{2}$. And its calculated Link-to-nodes ratio was 1.424. For N5, which has the same FAR (0.26),

Table 5 Macroscale urban morphological measures and the recorded UMI Walkscores

\begin{tabular}{|c|c|c|c|c|c|c|c|c|}
\hline Neighbor & Total area (ha) & $\begin{array}{l}\text { Total estimated } \\
\text { population }\end{array}$ & $\begin{array}{l}\text { Total gross } \\
\text { population density } \\
\text { (pph) }\end{array}$ & FAR & $\begin{array}{l}\text { Street intersect } \\
\text { density } / \mathrm{km}^{2}\end{array}$ & $\begin{array}{l}\text { Link-to- } \\
\text { nodes ratio }\end{array}$ & Block length (m) & Walk score \\
\hline N1 & 301 & 3312 & 11.02 & 0.11 & 40.20 & 1.50 & 180,270 & 49 \\
\hline $\mathrm{N} 2$ & 538 & 5652 & 10.51 & 0.18 & 39.78 & 1.49 & 350,560 & 47 \\
\hline N3 & 352 & 7272 & 20.66 & 0.18 & 59.38 & 1.50 & $150,180,240,270$ & 57 \\
\hline N4 & 140 & 4579 & 32.72 & 0.26 & 126.43 & 1.42 & $90,120,150$ & 57 \\
\hline N5 & 239 & 11,491 & 48.11 & 0.26 & 89.12 & 1.32 & 250,275 & 41 \\
\hline N6 & 465 & 12,188 & 26.20 & 0.38 & 72.69 & 1.44 & $150,180,240,300$ & 43 \\
\hline N7 & 144 & 6970 & 48.34 & 0.41 & 197.22 & 1.36 & $150,175,250,300$ & 50 \\
\hline
\end{tabular}


these figures came significantly lower as follows: $89.121 / \mathrm{km}^{2}$ for the former and 1.319 for the later (Table 5). On the other hand, regardless of the urban form pattern (orthogonal, curvilinear, or mixed), the effect of the Block Length seems to be more significant. It was spotted that the best UMI Walkscore of 57 was recorded for N4 with its least block length of 90-150 m, while the worst UMI Walkscore was recorded for N5 with its block length of 250-275 m, both with the same urban compactness indicators of FAR (0.26) but with N4 having much Street Intersect Density of $126.43 / \mathrm{km}^{2}$, which is directly correlated with Block Lengths. As shown in Figs. 8, 9a, b, these inconsistent considerations for proper walkability macroscale urban morphological indicators in the recent designs of the Emirati neighborhoods are depicted in the correlations between the recorded Walkscores on the one hand, and these indicators, as the measures for network compactness and connectivity, on the other hand.

Therefore, it could be concluded that while the urban density and compactness were significantly increased in at least some of the newly designed neighborhoods, the related urban morphology indicators were not influential enough in enhancing the obtained UMI Walkscores as they were not consistently considered in these designs.

\section{Impacts of macroscale urban planning indicators on UMI walkscore}

This section discusses the impacts of the other set of the walkability macroscale measures; the urban planning explicit and implicit indicators as defined in the
UMI plugin customized variables, on the recorded UMI Walkscores for the analyzed neighborhoods' designs.

As detailed in Table 6, the explicit macroscale urban planning indicators (including Land-use factors: the types and numbers of amenities, the amenities locational distribution in the neighborhood plan and their catchment distances), and the implicit macroscale urban planning measures (including Global and Destination Weights, seem to play a significant role in enhancing the recorded UMI Walkscores. For example, N7 that has the best indicators for urban morphological compactness, is having almost as low UMI Walkscore as N1 (the urban sprawling case), where it has an absent amenity (clinic) and a lower number of amenities than those with higher numbers of amenities such as N4 and N5, besides of course the Destination and Global Weights of the provided amenities. The more the available types and numbers of amenities, as well as the better locations of them in the neighborhood plan (mixed between the center and the edges of the neighborhood) reduces the catchment distances and thus increases the UMI Walkscore. This was noticed in N1 sprawling neighborhood rather than N7, where, strangely, N7 with its highest population density (48.34 pph) has almost the least types and numbers of amenities, and also the least efficient distribution of them as they are mostly located by the edges of the neighbourhood plan.

As shown in Table 3; Fig. 7 above, the apparent inappropriate locational distribution of the neighborhood amenities, even when more than enough number of amenities were locally provided (Table 6), has negatively affected the recorded UMI Walkscores. This is evident in almost all studied neighborhoods, especially N5.

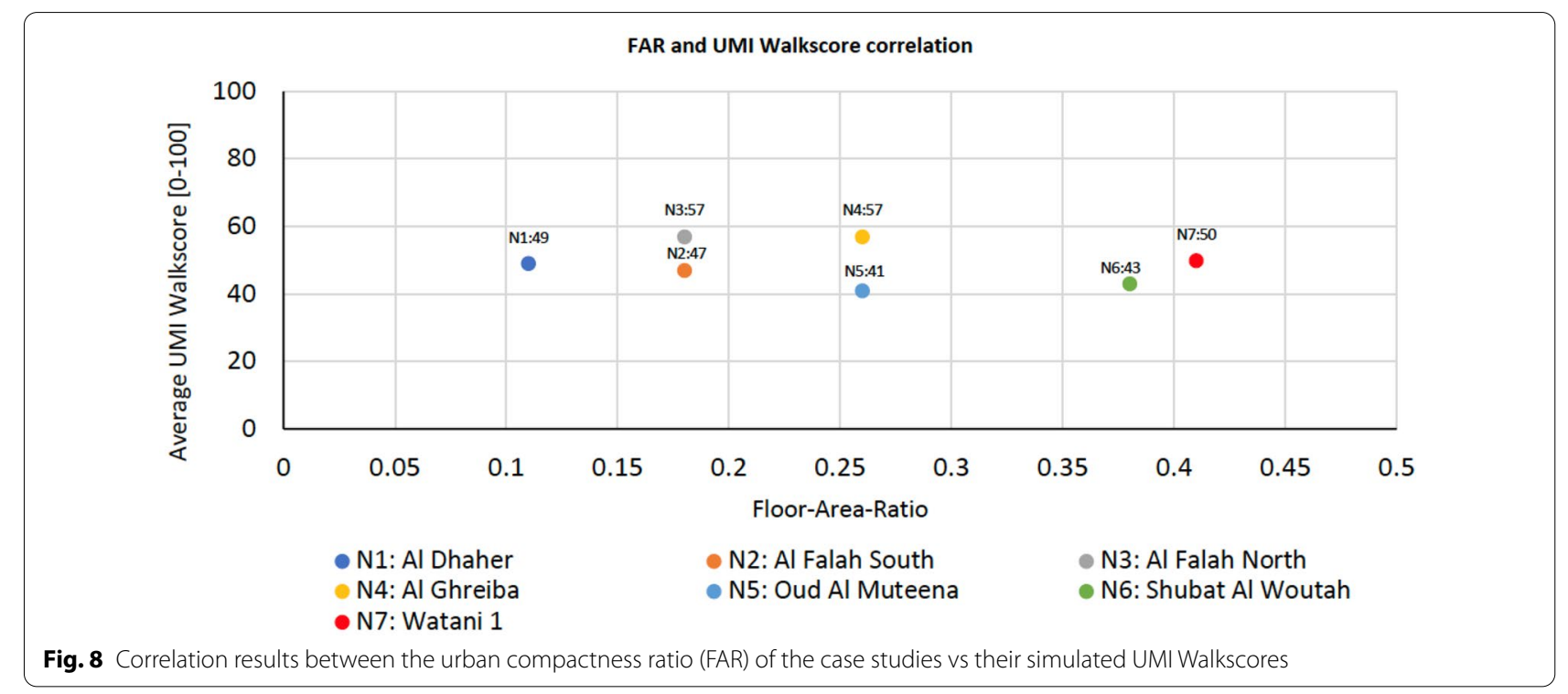




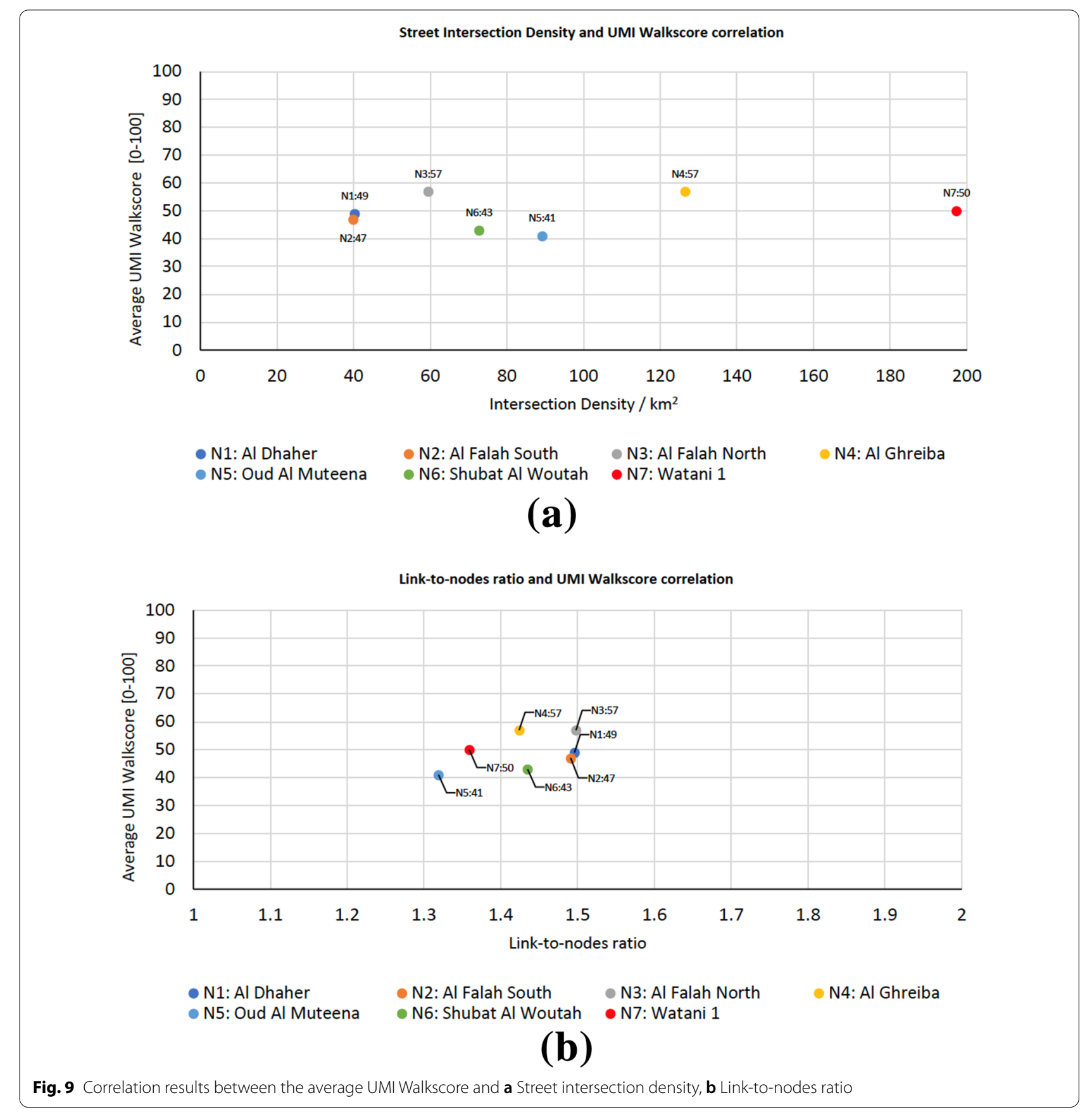

Obviously, the applied ranges of the catchment distances (between 350 and $800 \mathrm{~m}$ ) (Table 1) made it difficult to reach to an optimal locational distribution of the locally provided amenities in the design, especially in light of the still insufficient urban compactness indicators.

On the other hand, the types and numbers of the locally provided amenities were obviously inconsistent in all studied neighborhoods' designs (Table 6). It was expected that the more population/population density, the more the numbers and types of amenities would be considered in the design, but this was not the case. For example, in N4 neighborhood, the total population number was around 4579 persons and the provided amenities were as follows: 3 cafeterias, 4 groceries, 1 pharmacy, 2 retail shops, 1 school, 1 kindergarten, 2 mosques, 0 clinics, and 45 open/green spaces. Meanwhile, in N6, the total population number reached 12,188 person which is almost triple the number of the population in N4 neighborhood, 
Table 6 Macroscale urban planning measures and the resulting UMI Walkscore

\begin{tabular}{|c|c|c|c|c|c|c|c|c|}
\hline Neighbour & Type of amenities & $\begin{array}{l}\text { (Min.) } \\
\text { needed no. of } \\
\text { amenities }\end{array}$ & $\begin{array}{l}\text { Actual no. of } \\
\text { amenities in } \\
\text { design }\end{array}$ & $\begin{array}{l}\text { Locational } \\
\text { distribution } \\
\text { (center/edge/ } \\
\text { mixed) }\end{array}$ & $\begin{array}{l}\text { Max. required } \\
\text { catch } \\
\text { distances }\end{array}$ & $\begin{array}{l}\text { Global } \\
\text { weight }\end{array}$ & $\begin{array}{l}\text { Destination } \\
\text { (local) } \\
\text { weight }\end{array}$ & Walk score \\
\hline \multirow[t]{9}{*}{ N1 } & Cafeteria & 5 & 7 & Mixed & 800 & 3 & $10,8,6,4,2$ & 49 \\
\hline & Grocery & 3 & 8 & Mixed & 600 & 3 & $5,3,1$ & \\
\hline & Pharmacy & 1 & 1 & Edge & 800 & 3 & 1 & \\
\hline & Retail & 5 & 5 & Edges & 800 & 2 & $10,8,6,4,2$ & \\
\hline & School & 1 & 1 & Center & 800 & 2 & 1 & \\
\hline & Kindergarten & 2 & 1 & Edge & 350 & 3 & 5,3 & \\
\hline & Mosque & 1 & 9 & Mixed & 800 & 3 & 1 & \\
\hline & Clinic & 1 & 1 & Edge & 800 & 1 & 1 & \\
\hline & Green space & 1 & 5 & Edges & 800 & 2 & 1 & \\
\hline \multirow[t]{9}{*}{ N2 } & Cafeteria & 5 & 14 & Mixed & 800 & 3 & $10,8,6,4,2$ & 47 \\
\hline & Grocery & 3 & 12 & Mixed & 600 & 3 & $5,3,1$ & \\
\hline & Pharmacy & 1 & 1 & Center & 800 & 3 & 1 & \\
\hline & Retail & 5 & 9 & Mixed & 800 & 2 & $10,8,6,4,2$ & \\
\hline & School & 1 & 4 & Mixed & 800 & 2 & 1 & \\
\hline & Kindergarten & 2 & 3 & Mixed & 350 & 3 & 5,3 & \\
\hline & Mosque & 1 & 11 & Mixed & 800 & 3 & 1 & \\
\hline & Clinic & 1 & 0 & - & 800 & 1 & 1 & \\
\hline & Green space & 1 & 14 & Mixed & 800 & 2 & 1 & \\
\hline \multirow[t]{9}{*}{ N3 } & Cafeteria & 5 & 3 & Mixed & 800 & 3 & $10,8,6,4,2$ & 57 \\
\hline & Grocery & 3 & 4 & Mixed & 600 & 3 & $5,3,1$ & \\
\hline & Pharmacy & 1 & 2 & Center & 800 & 3 & 1 & \\
\hline & Retail & 5 & 3 & Mixed & 800 & 2 & $10,8,6,4,2$ & \\
\hline & School & 1 & 2 & Center & 800 & 2 & 1 & \\
\hline & Kindergarten & 2 & 1 & Center & 350 & 3 & 5,3 & \\
\hline & Mosque & 1 & 5 & Mixed & 800 & 3 & 1 & \\
\hline & Clinic & 1 & 1 & Edge & 800 & 1 & 1 & \\
\hline & Green space & 1 & 13 & Mixed & 800 & 2 & 1 & \\
\hline \multirow[t]{9}{*}{ N4 } & Cafeteria & 5 & 3 & Center & 800 & 3 & $10,8,6,4,2$ & 57 \\
\hline & Grocery & 3 & 4 & Mixed & 600 & 3 & $5,3,1$ & \\
\hline & Pharmacy & 1 & 1 & Center & 800 & 3 & 1 & \\
\hline & Retail & 5 & 2 & Center & 800 & 2 & $10,8,6,4,2$ & \\
\hline & School & 1 & 1 & Center & 800 & 2 & 1 & \\
\hline & Kindergarten & 2 & 1 & Center & 350 & 3 & 5,3 & \\
\hline & Mosque & 1 & 2 & Edge & 800 & 3 & 1 & \\
\hline & Clinic & 1 & 0 & - & 800 & 1 & 1 & \\
\hline & Green space & 1 & 45 & Mixed & 800 & 2 & 1 & \\
\hline \multirow[t]{9}{*}{ N5 } & Cafeteria & 5 & 2 & Edged & 800 & 3 & $10,8,6,4,2$ & 41 \\
\hline & Grocery & 3 & 5 & Mixed & 600 & 3 & $5,3,1$ & \\
\hline & Pharmacy & 1 & 0 & - & 800 & 3 & 1 & \\
\hline & Retail & 5 & 1 & Center & 800 & 2 & $10,8,6,4,2$ & \\
\hline & School & 1 & 0 & - & 800 & 2 & 1 & \\
\hline & Kindergarten & 2 & 1 & Center & 350 & 3 & 5,3 & \\
\hline & Mosque & 1 & 5 & Mixed & 800 & 3 & 1 & \\
\hline & Clinic & 1 & 0 & - & 800 & 1 & 1 & \\
\hline & Green space & 1 & 5 & Mixed & 800 & 2 & 1 & \\
\hline
\end{tabular}


Table 6 (continued)

\begin{tabular}{|c|c|c|c|c|c|c|c|c|}
\hline Neighbour & Type of amenities & $\begin{array}{l}\text { (Min.) } \\
\text { needed no. of } \\
\text { amenities }\end{array}$ & $\begin{array}{l}\text { Actual no. of } \\
\text { amenities in } \\
\text { design }\end{array}$ & $\begin{array}{l}\text { Locational } \\
\text { distribution } \\
\text { (center/edge/ } \\
\text { mixed) }\end{array}$ & $\begin{array}{l}\text { Max. required } \\
\text { catch } \\
\text { distances }\end{array}$ & $\begin{array}{l}\text { Global } \\
\text { weight }\end{array}$ & $\begin{array}{l}\text { Destination } \\
\text { (local) } \\
\text { weight }\end{array}$ & Walk score \\
\hline \multirow[t]{9}{*}{ N6 } & Cafeteria & 5 & 3 & Center & 800 & 3 & $10,8,6,4,2$ & 43 \\
\hline & Grocery & 3 & 3 & Mixed & 600 & 3 & $5,3,1$ & \\
\hline & Pharmacy & 1 & 1 & Center & 800 & 3 & 1 & \\
\hline & Retail & 5 & 2 & Center & 800 & 2 & $10,8,6,4,2$ & \\
\hline & School & 1 & 2 & Mixed & 800 & 2 & 1 & \\
\hline & Kindergarten & 2 & 1 & Center & 350 & 3 & 5,3 & \\
\hline & Mosque & 1 & 8 & Mixed & 800 & 3 & 1 & \\
\hline & Clinic & 1 & 0 & - & 800 & 1 & 1 & \\
\hline & Green space & 1 & 9 & Mixed & 800 & 2 & 1 & \\
\hline \multirow[t]{9}{*}{ N7 } & Cafeteria & 5 & 2 & Edges & 800 & 3 & $10,8,6,4,2$ & 50 \\
\hline & Grocery & 3 & 3 & Edges & 600 & 3 & $5,3,1$ & \\
\hline & Pharmacy & 1 & 1 & Edge & 800 & 3 & 1 & \\
\hline & Retail & 5 & 1 & Edge & 800 & 2 & $10,8,6,4,2$ & \\
\hline & School & 1 & 1 & Edge & 800 & 2 & 1 & \\
\hline & Kindergarten & 2 & 1 & Edge & 350 & 3 & 5,3 & \\
\hline & Mosque & 1 & 1 & Edge & 800 & 3 & 1 & \\
\hline & Clinic & 1 & 0 & - & 800 & 1 & 1 & \\
\hline & Green space & 1 & 44 & Edge & 800 & 2 & 1 & \\
\hline
\end{tabular}

but number of the provided amenities was almost the same or even less, except the mosques, as follows: 3 cafeterias, 3 groceries, 1 pharmacy, 2 retail shops, 2 schools, 1 kindergarten, 8 mosques, no clinics, and only 9 open/ green spaces. This inconsistency between the number of population and the number of the provided amenities in the recently designed neighborhoods might be partially referred to the remarkable absence of the consideration of the local walkability related guidelines and regulations in Abu Dhabi and Dubai (see Fig. 1; Appendix Table 7). In addition, as mentioned earlier, these local walkability related guidelines and regulations were themselves inconsistent with each other.

Inherently, population density is remarkably low in single-family housing neighborhoods in the UAE, either in the past or even in the recent designs, with some few exceptions such as in N5 and N7. In this study, population densities in the investigated neighborhoods were as low as $10.51 \mathrm{pph}$ in $\mathrm{N} 2$ and reached to a maximum rate of $48.34 \mathrm{pph}$ in N7 and 48.11 in N5 (Table 5). This would make the number and even some types of the proposed local amenities unfeasible to provide. Moreover, while being important in the UMI Walkscore calculations, the locally customized Destination and Global Weights for the different types of amenities, in both the designed neighborhoods and the local regulations and guidelines, were not considered.

Based on the overall results of the research, some insights related to walkability macroscale measures for the design of more pedestrian-friendly neighborhoods in the UAE, or even redeveloping the existing ones, could be proposed. Beside the necessity to keep adhering to the current trend of increasing urban form compactness, a combination of actions is envisaged to help boost the macroscale walkability measures. The first is to increase population density in a way that could support the economic feasibility of the locally provided amenities. Increasing population density can be achieved through introducing more dense housing patterns beside the currently inclusively developed single-family housing type. Introducing diversified types of amenities also requires introducing housing mixture that encourages social mix and, hence, different patterns of amenities would be required within the urban localities. Second, in addition to increasing FAR (through mainly reducing housing plot sizes) which ranged in the case studies between 0.11 in N1 and 0.41 in N7, more attention should be paid to other urban morphology compactness indicators including reducing Block Lengths, increasing Street Intersection Density, and to keep the Link-to-nodes ratio at the 
value of 1.40 or above. For example, increasing Street Intersection Density could be achieved by developing more 'gridiron' design pattern for pedestrian networks with minimized loops and dead-end streets (CNU 2019).

Third, is locating local amenities in more appropriate spots, especially in both the center and the edges, within each neighborhood. This could help overcome the problem of accessibility, even partially. Fourth, is the consideration of both the Destination Weights and Global Weights of the provided amenities after defining the really needed numbers and types of these locally provided amenities, especially in light of the absence of a unified and clear definition of them either in theory (local guidelines and regulations) or practice (recent neighborhood designs). Accurate definition of the truly required numbers and types of local amenities with their credible Destination and Global Weights, is fundamental in urging people walk to them. The obvious disparities among the regulations, guidelines and practices indicate that there is a need for a correctly 'customized' set of regulations related to the types and numbers of the amenities that credibly suite local community needs. Local community residents themselves, not the planning theories nor the theoretical local planning guidelines and regulations, should have the lead in defining these sets of amenitiesrelated measures. Local residents should be consulted in this process through administered questionnaires and interviews. As community needs might change over time, so in response, these customized measures of amenities should be 'resilient'. They should be re-assessed periodically to assure that they respond effectively to the changing needs of the local community for which they are tailored. Currently, there is a lack of such a resilience mechanism that would help continuously review the defined guidelines and regulations pertaining to the locally provided amenities in the Emirati neighborhoods. Designed to be resilient and adaptive, the use and/ or location of the locally provided amenities should be effortlessly changed over time, when and where this is needed.

Fifth, is the provision of reliable, rapid and affordable public transportation system (actually as part of the missing amenities), with accessible catchment distances. Currently, there is almost total absence of public transportation nodes that penetrates inside the studied neighborhoods, except in the Dubai case, even partially. Practically speaking, some of the locally provided amenities (in design) might not be actually used, due to the high car ownership rates in the UAE, which has increased the impact of 'choice' among residents (Barton 2000). This made it more convenient for the residents to satisfy their needs away from their own locality. So, walking to transportation nodes (mainly bus stops on the neighborhood level) sounds an essential, still absent, measure that might be a good solution rather than attempting to provide all needed amenities locally. This would allow people to choose among various amenities of the same types even if they were not provided locally due to the lack of economic feasibility as a result of the low population density, while not using their own cars. For sure, this policy would require effective incentives to urge people to use public transportation instead of their own cars.

Finally, it might be claimed that the results of this research in terms of its in-depth investigation of the effect of walkability macroscale urban morphological and urban planning indicators on UMI Walkscores, would enrich the global debate about HPT in general and walkability in specific (for example: Brookfield 2017; Rogers et al. 2013; Paranagamage et al. 2014; Mazumdar et al. 2018). Walkability boosting issues as discussed in this research including the need for a consistent consideration for dense urban morphology measures and the 'customization' of the required numbers, types, and Destination and Global Weights of amenities, beside the 'resilience' of these customized parameters, are not only beneficial for the case of the UAE but might be applicable in other parts of the world, as well.

\section{Conclusions}

As a part of their rigorous efforts to achieve urban sustainability, the local and federal housing authorities in the UAE have significantly changed the morphology of the designs of recent neighborhoods into denser and more compact urban forms that have been expected to enhance walkability, through enhancing the macroscale measures. This is perceived to consequently contribute to developing more environmentally, socially, and economically sustainable communities. Utilizing the UMI computational simulation tool with its more comprehensive and customizable walkability-related variables helped calculating and compared walkability scoring (UMI Walkscore) for the recent compact designs of neighborhoods.

The first research question about the customization of the UMI Walkscore variables, related to macroscale urban planning measures of Land-use (required types and numbers of amenities, their minimum and maximum catchment distances, and their Destination and Global Weights), was answered in a way that made utilizing UMI Walkscore possible in the UAE context with its totally different urban context than the UMI's default variables tailored for the USA context. Still, this was by no means easy as the fragmented, even sometime, conflicting official regulations and guidelines made it difficult to define all these variables easily.

After customizing the Walkscore variables the second research question was answered through applying 
the UMI Walkscore simulation on the investigated case studies. The recent denser and more compact neighborhoods recorded various Walkscores, but none has exceeded the 'somewhat walkable' neighborhood benchmark. Some even recorded Walkscores close to the urban sprawling neighborhood model. In all cases, the recorded UMI Walkscores were much lower than the targeted 'Walker's Paradise' benchmark score. So, it seems that the urban compactness of the recently designed neighborhoods in Abu Dhabi and Dubai have not satisfactorily enhanced walkability compared to the conventional urban sprawling neighborhood pattern. This would hinder the full realization of sustainable neighborhoods as with less walking, people encountering, social capital, sense of safety and security, and physical and mental health would be significantly absent. In addition, more reliance on private cars for comminuting to local services and amenities would adversely affect purity of air while increasing greenhouse gas emissions and the level of noise.

The answer for the third research question came to explain why this has happened by exploring the impact of walkability macroscale measures of both the urban morphology and urban planning on the recorded UMI Walkscores for the assessed neighborhoods. Inconsistent consideration for urban morphological compactness factors of FAR, Street Intersection Density, Block Lengths, and Link-to-nodes ratio was observed among the studied neighborhoods. Reducing the housing plot sizes in the neighborhoods designs has apparently received the main attention that explains the observed increase in FAR. Meanwhile, the other important urban morphological measures which are even more influential for walkability such as Link-to-nodes ratio, Street Intersection Density, and Block Length, have not apparently received the same attention. But even when most of them have been considered, as in the case of N7 neighborhood, the UMI Walkscore remains low. On the other hand, the walkability macroscale urban planning measures including explicit land-use factors (types and numbers of amenities, their locational distribution and catchment distances) and implicit factors (Destination and Global Weights), which proved being influential for UMI Walkscores, were overlocked in the recent neighborhoods' design.

So, besides admitting that urban compactness per se is not a sufficient design measure for enhancing walkability in local communities, and that the macroscale urban planning measure are significant in this regard, the research proposed a five-actions plan to help boost walkability macroscale measures in the design of local urban communities in the UAE. This proposed plan highlights the essential role of local residents in the customization of walkability macroscale urban planning design measures to be tailored for their local communities, especially in light of the wide gabs among local regulations and guidelines, on the one hand, and the actual designs, on the other hand. In addition, these customized design measures should be revisited periodically to assure their continuous suitability to local communities because the types and numbers of the locally provided amenities and the accepted catchment distances to them could change over time. This applies also to their customized Global and Destination Weights. In other words, planning for the local amenities of walkable urban communities should consider both local customization and resilience of the design measures to keep being sustainable.

On the other hand, while it might be understood that with lower population density (such as in the cases of $\mathrm{N} 2,3,4,6$ ) less types and number of amenities might be provided but it is puzzling to see that this was the case for N5 and N7 neighbourhoods which have almost ideal gross density and urban morphology compactness measures. Neighborhoods designs like these should not be granted a development permit by the concerned local authorities. Lower than $50 \mathrm{pph}$ neighborhoods should not be allowed to make sure that the provided amenities in terms of sufficient types and numbers will be economically viable. The significantly low population density, as noticed in all new designs of urban communities in the UAE, would make any rectifying action for boosting walkability, such as increasing numbers and diversifying the types of amenities, not economically feasible. Therefore, increasing population density through urban densification might be practically considered the first essential step in this regard. Furthermore, walkability to easily accessible public transportation nodes (bus stops) linking the community with other neighboring facilities, seems another necessary action. This would overcome the problem of low population density and enable people to choose among various amenities in the surroundings localities as well.

While the applied method in this research could be replicated in any other urban context, as long as the customization of locally provided amenities and their resilience are considered, it should be acknowledged that in this research walkability scores were quantitatively calculated based on the walkability macroscale measures including the pedestrian network connectivity, catchment areas, locational distribution and weights of amenities. Despite the recognized significance of these quantitative parameters, there are other microscale urban design effective, mostly qualitative, such as widths of pedestrian walkways, safety measures, street detailed cross section with frontage, furnishing, etc. factors that have been out of the 
scope of this research. Accordingly, to enrich the research about the HPT in general, and the design for walkability in particular, these other fine-grain urban design influential measures should be investigated in further research. Also, even for the macroscale walkability measures, the research findings should be perceived within the extent of the measured indicators as per the utilized walkability simulation tool of the UMI Walkscore. Other macroscale measures that might be missing from this simulation tool are not covered in this research.

\section{Appendix 1}

See Table 7

Table 7 The regulations for amenities and catchment distances in Dubai

\begin{tabular}{|c|c|c|c|}
\hline Amenity level & Amenity type & No. of residents & Catchment distance (m) \\
\hline \multicolumn{4}{|l|}{ Less than $70 \mathrm{pph}$} \\
\hline \multirow[t]{6}{*}{ Neighborhood level } & Daily prayer mosque & 2000 & 500 \\
\hline & Retail shops & 2000 & 400 \\
\hline & Post office boxes & 2000 & 400 \\
\hline & Public space (plaza) & 2000 & 400 \\
\hline & Children play zone (optional) & 2000 & 400 \\
\hline & Neighborhood garden & 2000 & 400 \\
\hline \multirow[t]{10}{*}{ Residential region level } & Friday mosque & 6000 & 1000 \\
\hline & Shopping center & 6000 & 800 \\
\hline & Nursery & 6000 & 800 \\
\hline & Kindergarten (KG) & 6000 & 800 \\
\hline & Primary school & 6000 & 800 \\
\hline & Private general clinic & 6000 & Not specified \\
\hline & Private specialized clinic & 6000 & Not specified \\
\hline & Private medical center & 6000 & Not specified \\
\hline & Public plaza (optional) & 6000 & 800 \\
\hline & Region park & 6000 & 800 \\
\hline \multicolumn{4}{|l|}{ Between 70 and 220 pph } \\
\hline \multirow[t]{6}{*}{ Neighborhood level } & Daily prayer mosque & 3000 & 500 \\
\hline & Retail shops & 3000 & 350 \\
\hline & Post office boxes & 3000 & - \\
\hline & Public space (plaza) & 3000 & 350 \\
\hline & Children play zone (optional) & 3000 & 350 \\
\hline & Neighborhood garden & 3000 & 350 \\
\hline \multirow[t]{10}{*}{ Residential region level } & Friday mosque & 9000 & 1000 \\
\hline & Shopping center & 9000 & 650 \\
\hline & Nursery & 9000 & 650 \\
\hline & Kindergarten (KG) & 9000 & 650 \\
\hline & Primary school & 9000 & Not specified \\
\hline & Private general clinic & 9000 & Not specified \\
\hline & Private specialized clinic & 9000 & Not specified \\
\hline & Private medical center & 9000 & Not specified \\
\hline & Public plaza (optional) & 9000 & 800 \\
\hline & Region park & 9000 & 800 \\
\hline \multicolumn{4}{|l|}{ More than 220 pph } \\
\hline \multirow[t]{6}{*}{ Neighborhood level } & Daily prayer mosque & 4000 & 500 \\
\hline & Retail shops & 4000 & 300 \\
\hline & Post office boxes & 4000 & - \\
\hline & Public space (plaza) & 4000 & 300 \\
\hline & Children play zone (optional) & 4000 & 300 \\
\hline & Neighborhood garden & 4000 & 300 \\
\hline
\end{tabular}


Table 7 (continued)

\begin{tabular}{|c|c|c|c|}
\hline Amenity level & Amenity type & No. of residents & Catchment distance $(\mathrm{m})$ \\
\hline \multirow[t]{10}{*}{ Residential region level } & Friday mosque & 12,000 & 1000 \\
\hline & Shopping center & 12,000 & 500 \\
\hline & Nursery & 12,000 & 500 \\
\hline & Kindergarten (KG) & 12,000 & 500 \\
\hline & Primary school & 12,000 & Not specified \\
\hline & Private general clinic & 12,000 & Not specified \\
\hline & Private specialized clinic & 12,000 & Not specified \\
\hline & Private medical center & 12,000 & Not specified \\
\hline & Public plaza (optional) & 12,000 & 500 \\
\hline & Region park & 12,000 & 600 \\
\hline
\end{tabular}

\section{Acknowledgements}

The researcher would like to thank the Emirates Center for Happiness Research at the United Arab Emirates University and the Research Assistants how contributed to this research project.

\section{Authors' contributions}

KGA: the main author, significantly contributed to developing the literature review, case studies, and the results' Analysis. Shared the discussion and conclusions with the second author. SMH: significantly applied the UMI software simulation. Shared the discussion and conclusions with the first corresponding author. All authors read and approved the final manuscript.

\section{Funding}

This research is Funded by the Emirates Center for Happiness Research at the United Arab Emirates University, Grant Code G00003226.

\section{Availability of data and materials}

All data generated or analyzed during this study are included in this published article [and its supplementary information files].

\section{Declarations}

\section{Competing interests}

The authors declare that they have no competing interests.

\section{Author details}

${ }^{1}$ Emirates Center for Happiness Research, United Arab Emirates University, Al Ain 15551, UAE. ${ }^{2}$ Architectural Engineering Department, College of Engineering, United Arab Emirates University, P. O. Box: 13393, Al Ain, UAE. ${ }^{3}$ Architectural Engineering Department, College of Engineering, United Arab Emirates University, Al Ain, UAE.

Received: 16 December 2020 Accepted: 2 August 2021

Published online: 14 August 2021

\section{References}

Abu Dhabi Housing Authority (ADHA) (2016) Abu Dhabi national housing guidelines for integrated communities, planning guidelines. V 1.0. ADHA, Abu Dhabi

Abu Dhabi Urban Planning Council (2014a) Abu Dhabi community facility planning standards, standards report. Version 1.0. ADUPC, Abu Dhabi

Abu Dhabi Urban Planning Council (2014b) Abu Dhabi public realm design manual. ADUPC, Abu Dhabi
Abu Dhabi Urban Planning Council. The Pearl Community Rating System. http://estidama.upc.gov.ae/template/estidama/docs/PCRS\%20Version\% 201.0.pdf. Accessed 6 May 2019

Abu Dhabi Urban planning Council (2015) Abu Dhabi urban street design manual. Abu Dhabi Urban planning Council, Abu Dhabi

Allen A (2009) Sustainable cities or sustainable urbanisation? Perspective, Summer 2009 edition of 'palette.' Ucls J Sustain Cities 12:1

American Society of Landscape Architects (2015) professional practice: sustainable urban development. https://www.asla.org/sustainableurba ndevelopment.aspx. Accessed 13 Feb 2015

Annunziata A et al (2020) A literature review on walkability and its theoretical framework. Emerging perspectives for research developments. International Conference on computational science and its applications. Springer, Cham, pp 422-437

Barton H (2000) Sustainable communities. Earthscan Publications Ltd., Cambridge

Brookfield K (2017) Residents' preferences for walkable neighborhoods. J Urban Des 22(1):44-58. https://doi.org/10.1080/13574809.2016.1234335

Brown, Tom (2015) Walk score and your community. http://strafford.org/ magazine/walk-score-and-your-community/. Accessed 30 Jan 2019

Burton E, Jenks M, Williams K (2013) Achieving sustainable urban form. Routledge, London

CNU (Congress for the New Urbanism) (2019) street networks 101. https:// www.cnu.org/our-projects/street-networks/street-networks-101. Accessed 12 Mar 2019

EnviroAtlas (2019) Estimated intersection density of walkable roads: fact sheet. https://enviroatlas.epa.gov/enviroatlas/DataFactSheets/pdf/Supplement al/Estimatedintersectiondensityofwalkableroads.pdf. Accessed 4 Apr 2019

Frank LD et al (2021) Comparing walkability methods: creation of street-smart walk score and efficacy of a code-based 3D walkability index. J Transp Health 21:101005

Frey H (1999) Designing the city: towards a more sustainable urban form. Spon Press, London

Garau C et al (2020) A walkability assessment tool coupling multi-criteria analysis and space syntax: the case study of Iglesias, Italy. Eur Plan Stud. https://doi.org/10.1080/09654313.2020.1761947

Khaled GA (2020) Sustainable modes of mobility in new urban neighborhoods in UAE: assessing walkability and bikeability. In: Al-Masri A, Al-Assaf Y (eds) Sustainable development and social responsibility_ch 33, vol 2. Springer, Berlin. https://doi.org/10.1007/978-3-030-32902-0 33

Jones C, MacDonald C (2004) Sustainable urban form and real estate markets. The Proceedings of the Annual European Real Estate Conference, 2-5 June. Milan, Annual European Real Estate Conference

Arwa KS, Khaled GA (2019) Replacing land-use planning with localized formbased codes in the United Arab Emirates: a proposed method. Land 8(3):47. https://doi.org/10.3390/land8030047 
Labdaoui Ket al (2021) Utilizing thermal comfort and walking facilities to propose a comfort walkability index (CWI) at the neighborhood level. Build Environ 193:107627

Moreno C, Allam Z, Chabaud D, Gall C, Pratlong F (2021) Introducing the "15-minute city": sustainability, resilience and place identity in future post-pandemic cities. Smart Cities 4(1):93-111

Neuman M (2005) The compact city fallacy. J Plan Educ Res 25:11-26

Clerk M (2000) A treatise on electricity and magnetism. In: Jenks M, Burgess R (eds) Compact cities sustainable urban forms for developing countries, vol 2, 3rd edn. Spon Press, London, pp 68-73

Koohsari MJ, Sugiyama T, Hanibuchi T, Shibata A, Ishii K, Liao Y, Oka K (2018) Validity of Walk Score ${ }^{\circledR}$ as a measure of neighborhood walkability in Japan. Prev Med Rep 9:114-117

Koschinsky J, Talen E, Alfonzo M, Sungduck L (2017) How walkable is Walker's paradise? Environ Plann B Plann Des 44(2):343-363

Kowaleski-Jones L, Zick C, Ken RS, Brown B, Hanson H, Fan J (2018) Walkable neighborhoods and obesity: evaluating effects with a propensity score approach. Popul Health 6:9-15

Masoud M (2011) Evaluation of social capital, considering sociability and walkability in urban fabrics: the case of Isfahan City, Iran. Asian Social Sci $7(10): 216-228$

Mazumdar S, Learnihan V, Cochrane T, Davey R (2018) The built environment and social capital: a systematic review. Environ Behav 50(2):119-158

Paranagamage P, Price A, Khandokar F, Austin S (2014) Urban design and social capital: lessons from a case study in Braunstone, Leicester. 3rd World Construction Symposium: sustainability and development in built environment Proceedings. Sri Lanka, Ceylon Institute of Builders

Planning Department, Dubai Government. (2018) Community facilities standards. https://www.dm.gov.ae/en/Business/PlanningAndConstruction/ Documents/Planning\%20Standards/Community+facilities+standards+ list.pdf. Accessed 12 June 2018
Kiflen R, Thielman J, Manson H, Public Health Ontario (Ontario Agency for Health Protection and Promotion) (2018) Evidence brief: neighborhood walkability and type 2 diabetes. Queen's Printer for Ontario, Toronto

Reliance Foundry (2018) What are walk score and walk appeal?. https:// www.reliance-foundry.com/blog/walk-score-and-walkable-cities\#gref. Accessed 17 Dec 2018

Rogers H, Gardner K, Carlson C (2013) Social capital and walkability as social aspects of sustainability. Sustainability 5:3473-3483

Rundle AG et al (2019) Development of a neighborhood walkability index for studying neighborhood physical activity contexts in communities across the US over the past three decades. J Urban Health 96(4):583-590

Trimarchi M. (2018) What's a walk score?. https://science.howstuffworks.com/ environmental/green-science/walk-score1.htm. Accessed 24 July 2018

Singh K, Murari SI, Narahari SI, Denis AS (2018) Design and analysis of human powered hybrid vehicle. Int J Mech Eng Technol 9(4):594-605

Schiller B (2015) Live in a walkable neighborhood? You get to be thinner and healthier. https://www.fastcompany.com/3054231/live-in-a-walkableneighborhood-you-get-to-be-thinner-and-more-healthy. Accessed 23 Nov 2018

Sustainble Design Lab (2020) Urban Modeling: umi. http://web.mit.edu/susta inabledesignlab/projects/umi/index.html. Accessed 21 June 2020

URBACT (2019) Densification beyond the city centre: urban transformation against sprawl. https://urbact.eu/densification-beyond-city-centreurban-transformation-against-sprawl. Accessed 12 April 2019

Walk Score (2019) Walk Score Methodology. https://www.walkscore.com/ methodology.shtml. Accessed 2 June 2019

\section{Publisher's Note}

Springer Nature remains neutral with regard to jurisdictional claims in published maps and institutional affiliations.

\section{Submit your manuscript to a SpringerOpen ${ }^{\odot}$ journal and benefit from:}

- Convenient online submission

- Rigorous peer review

- Open access: articles freely available online

- High visibility within the field

- Retaining the copyright to your article

Submit your next manuscript at $\boldsymbol{\nabla}$ springeropen.com 